Cita bibliográfica: Celdrán-Bernabeu, M.A.; Mazón, J.-N. y Giner Sánchez, D. (2018). Open Data y turismo. Implicaciones para la gestión turística en ciudades y destinos turísticos inteligentes. Investigaciones Turísticas (15), pp. 49-78. http://dx.doi.org/10.14198/INTURI2018.15.03

\title{
Open Data y turismo. Implicaciones para la gestión turística en ciudades y destinos turísticos inteligentes*
}

\section{Open Data and tourism. Implications for tourism management in Smart Cities and Smart Tourism Destinationss}

Marco A. Celdrán-Bernabeu. Universidad de Alicante, España. ma.celdran@ua.es

José-Norberto Mazón. Universidad de Alicante, España. inmazon@ua.es

David Giner Sánchez. Invat.tur, España. davidginersanchez@gmail.com

\section{RESUMEN}

La irrupción de Internet y el progresivo despliegue de las tecnologías de la información y comunicación (TIC), ha generado interesantes oportunidades para la planificación y gestión de las ciudades y destinos turísticos del siglo XXI. En este escenario, los entornos urbanos producen una gran cantidad de datos como consecuencia directa del uso intensivo de las TIC. Este trabajo se aproxima al concepto de Open Data desde dos hipótesis. Por una parte, que su aplicación en el ámbito del turismo puede generar un ecosistema innovador que mejore la experiencia turística, gracias al diseño de productos y servicios TIC. Y por otra, que su grado actual de aplicación en turismo es bajo y necesita de medidas de apoyo. Con el fin de corroborarlas, se plantean dos objetivos. En primer lugar, y desde una vertiente teórico-conceptual, profundizar en la terminología de Open Data, conceptos relacionados y sus implicaciones para la gestión turística. En segundo lugar, conocer su grado de aplicación actual en el turismo, para proponer recomendaciones que favorezcan su uso. Con este fin, se analizan los conjuntos de datos abiertos en turismo de las ciudades de la Red Española de Ciudades Inteligentes (RECI). Este trabajo constituye un punto de partida en la investigación de las relaciones entre Open Data y turismo.

Palabras clave: datos abiertos, ciudades inteligentes, destinos turísticos inteligentes, TIC.

\footnotetext{
* El presente trabajo se enmarca en el proyecto de investigación "Análisis de procesos de planificación aplicados a ciudades y destinos turísticos inteligentes. Balance y propuesta metodológica para espacios turísticos: Smart Tourism Planning". Proyecto CSO2017-82592-R del Programa Estatal de I+D+i del Ministerio de Economía, Industria y Competitividad.
} 


\section{ABSTRACT}

The emergence of the Internet and the spread of information and communication technologies (ICT) have generated interesting opportunities for the planning and management of cities and tourism destinations of the twenty-first century. In this scenario, urban environments produce a large amount of data as a direct consequence of the intensive use of ICTs. This study addresses the concept of Open Data from two assumptions. On the one hand, that its application in the field of tourism can generate an innovative ecosystem that improves the tourist experience, thanks to the design of ICT products and services. And, on the other, that its current degree of application in tourism is low and needs support measures. In order to corroborate these assumptions, two objectives are proposed. First, and from a theoretical-conceptual perspective, to deepen the terminology of Open Data, related concepts and their implications for tourism management. Second, to determine their current degree of application in tourism, in order to propose recommendations that favor their use. To this end, the Open Data sets in tourism of the Spanish Network of Smart Cities (RECl) are analyzed. This study constitutes a starting point in the research of the relationships between Open Data and tourism.

Keywords: open data, smart cities, smart tourism Destinations, ICT

\section{INTRODUCCIÓN}

Uno de los principales retos de la sociedad actual es resolver los problemas de las ciudades del siglo XXI, que viven inmersas en distintas problemáticas (Abellá-García, Ortizde-Urbina-Criado y De-Pablos-Heredero, 2015). Pero son fundamentalmente dos las que han catalizado la aparición de nuevos paradigmas de gestión urbana. Por un lado, la intensificación de los procesos de urbanización desde mediados del siglo XX (Naciones Unidas, 2014), que si bien tienen el potencial de hacer que las ciudades sean más prósperas, implican cambios multi-dimensionales para los que no siempre están preparadas. Muchas de estas ciudades siguen modelos insostenibles, desde diferentes dimensiones (ONU-HABITAT, 2016:5). Ambientalmente, el modelo actual genera una sub-urbanización de baja densidad que conlleva un mayor gasto de energía y contribuye al cambio climático. Socialmente, genera múltiples desigualdades, exclusión y privación, dando lugar a zonas divididas en la ciudad. Económicamente, es insostenible debido a la generalización del desempleo y el trabajo inestable, que da lugar a dificultades económicas y un acceso desigual a los servicios y equipamientos urbanos.

Por otro lado, el desarrollo de Internet y el avance de las tecnologías de la información y comunicación (TIC, en adelante), han sido el percutor de la denominada revolución digital. El despliegue de las TIC sobre la ciudad puede generar un ecosistema innovador apoyado en la innovación y una mejor gestión de las infraestructuras y servicios de la ciudad. Estas aplicaciones deben repercutir de manera clara en el ciudadano, para lo que es indispensable una implementación tecnológica planificada que no genere desigualdades o brechas digitales. En este sentido, el Internet de las Cosas (IoT, en adelante) parece ser una de las tecnologías más valoradas actualmente (Ditrendia, 2017), que mediante una red de sensores permite generar una infraestructura tecnológica que monitoriza la ciudad en tiempo real, generando datos de enorme utilidad para la gestión de los servicios (Libelium, 2017). Del mismo modo, la hiperconectividad, derivada del incremento exponencial de la capacidad de conexión de máquinas o 
dispositivos (PwC y IEBS, 2015), ha generado un escenario de "datificación" desconocido hasta la fecha (Newell y Marabelli, 2015) donde el smartphone es uno de los elementos principales. En España, según el informe de Indicadores destacados de la Sociedad de la Información (ONTSI, 2017) el número de líneas de telefonía móvil alcanza los 51,86 millones, lo que supone una penetración del 111,5\%. Existen más líneas de telefonía móvil activas que habitantes. De acuerdo al informe de Cisco (2016), en 2021 habrá en el mundo más teléfonos móviles (5.500 millones) que cuentas bancarias ( 5.400 millones), suministros de agua corriente (5.300 millones) o líneas de telefonía fija (2.900 millones). En este mundo hiperconectado, los sensores y dispositivos móviles interactúan y registran una enorme cantidad de datos (Hedman, Srinivasan y Lindgren, 2013), que además pueden ser compartidos en las redes sociales (Chung y Koo, 2015).

En este contexto de cambio socio-tecnológico, surgen desde mediados de los años 90 nuevos enfoques de planificación y gestión urbana, entre los que destaca el enfoque Ciudad Inteligente o Smart City (Caragliu, Del Bo, y Nijkamp, 2011; Pierce, Ricciardi, y Zardini, 2017). Este enfoque se caracteriza por un elevado grado de aplicación de las nuevas tecnologías, que considera clave para la obtención de una mejora en la calidad de vida, de las condiciones sociales, económicas y medioambientales de estas áreas urbanas, gracias a su implementación en la gestión de las infraestructuras de las ciudades (Guo, Liu, y Chai, 2014; Komninos, Schaffers y Pallot, 2011). A pesar de que no existe unanimidad en su definición (Albino, Berardi, y Dangelico, 2015; Caragliu, Del Bo, y Nijkamp, 2011; Nam y Pardo, 2011), la ciudad inteligente puede ser entendida como "una ciudad que se desenvuelve con visión de futuro en la economía, las personas, la gobernanza, la movilidad, el medioambiente y la vida, basada en la combinación inteligente de dotaciones y actividades de ciudadanos autónomos, independientes y conscientes" (Giffinger, 2007). La ciudad inteligente se configura como un centro de innovación que busca soluciones a los problemas económicos, sociales y ambientales de las urbes del siglo XXI (Vanolo, 2014). Para Moreno (2015:90), la ciudad inteligente tiene un carácter holístico, siendo el elemento principal de la misma el ciudadano, como destinatario final de la trasformación urbana. Por este motivo sus aspectos más importantes giran en torno a la calidad de vida, la innovación, la capacitación, la accesibilidad, etc. Mientras que los aspectos puramente tecnológicos se perciben como instrumentales.

A pesar de ser un enfoque con interesantes oportunidades, arrastra críticas desde diferentes perspectivas (Fernández, 2015; Fernández-Güell, 2015; March y Ribera-Fumaz, 2014; Kitchin, 2014). Como señala Fernández-Güell (2015:23), si bien presenta oportunidades, este enfoque va ligado a iniciativas que resultan en ocasiones desmesuradas, con costes muy elevados y con retornos a largo plazo que no siempre pueden ser asumidos por las administraciones de ciudades pequeñas e intermedias. Además, la mayoría de estos proyectos de ciudad inteligente tienen un fuerte carácter sectorial, al estar dirigidas a cuestiones muy concretas y no enfocarse desde una perspectiva más integral. A ello se unen otros riesgos, como la intromisión en la privacidad, iniciativas que incrementen el metabolismo urbano y aumenten los consumos energéticos y las emisiones contaminantes, o la falta de presupuesto para generar la infraestructura de conectividad que necesita el ecosistema de la ciudad inteligente. Esto ha provocado que surjan numerosos interrogantes motivados por su falta de claridad conceptual, que muchas veces se queda en renderizados futuristas, complejos diagramas de servicios urbanos interconectados y un lenguaje técnico muy alejado de la ciudadanía (Fernández, 2015: 44). Lo que parece un hecho irrefutable, es que la tecnología es un instrumento de la ciudad 
inteligente, pero no un fin en sí mismo. El foco de atención debe ser el ciudadano y la mejora de sus servicios y calidad de vida, teniendo siempre como pilar de referencia la mejora de la sostenibilidad, la innovación y la gobernanza.

La Unión Europea ha desarrollado desde mediados de los años 90 distintos programas y políticas para transformar las ciudades tradicionales en Ciudades Inteligentes o Smart Cities. Destaca en este sentido la Estrategia Europa 2020 (Comisión Europea, 2010), que apuesta por un crecimiento inteligente, con una economía basada en el conocimiento y la innovación, un crecimiento sostenible, donde la economía hace un uso más sostenible de los recursos, y un crecimiento integrador, con una economía que promueva altos niveles de empleo que tenga cohesión social y territorial. Con este objetivo, propone una Agenda Digital para Europa, que acelere el despliegue de internet a alta velocidad y beneficiarse de un mercado único digital para las familias y empresas. La apuesta financiera por el desarrollo de las "Smart Cities" se inicia en el VII Programa Marco (2007-2013), con el objetivo de contribuir a la sostenibilidad de los entornos urbanos, mejorar la eficiencia de los servicios, reducir la huella de carbono en las ciudades y estimular la creación de un entorno innovador para el desarrollo de empresas de base tecnológica (Villarejo, 2015:35).

A nivel nacional, el impulso a las Ciudades Inteligentes ha venido dado a través de programas como el Plan Nacional de Ciudades Inteligentes (2015-2017) (Ministerio de Industria, Energía y Turismo, 2015), enmarcado en la Agenda Digital para España (Ministerio de Industria, Energía y Turismo, 2013). Este plan tenía una estrategia centrada en tres ámbitos: normalización, apoyo a la industria y gobernanza. No obstante, un hito es la fundación en 2012 de la Red Española de Ciudades Inteligentes (RECI). Formada por 81 ciudades, esta asociación promueve la puesta en marcha de Ciudades Inteligentes que gestionen de manera automática y eficiente las infraestructuras y los servicios urbanos, así como la mejora de la calidad de los servicios. Para la RECI la innovación y el conocimiento, junto con las TIC, son los aspectos esenciales que van a guiar las ciudades del siglo XXI, favoreciendo de esta manera un espacio innovador que fomente el talento, las oportunidades y la calidad de vida en el entorno urbano ( $\mathrm{RECl}, 2017)$. En diciembre de 2017, el Ministerio de Energía, Turismo y Agenda Digital aprueba el Plan Nacional de Territorios Inteligentes (2017-2020), que pretende dar continuidad al primer Plan Nacional de Ciudades Inteligentes (2015-2017) orientándose hacia tres campos de acción: "Acciones territoriales", "Acciones de soporte" y "Acciones complementarias". Su principal objetivo es impulsar la aplicación de las TIC al funcionamiento de las ciudades, el turismo, las zonas rurales o los servicios públicos con el objetivo de mejorar la eficiencia y el desarrollo económico, social y ambiental de las entidades (Ministerio de Energía, Turismo y Agenda Digital, 2017).

El enfoque de ciudad inteligente se ha trasladado al entorno turístico de la mano de los destinos turísticos inteligentes (DTI, en adelante) o smart tourism destinations (Baggio y Cooper, 2015), donde resulta especialmente interesante al permitir evolucionar hacia una planificación sustentada en la generación de conocimiento y la innovación, con una fuerte componente tecnológica asociada (Huang, Goo, Nam, y Woo, 2017). A este respecto, España es uno de los países que lidera el desarrollo de DTI, que se inicia con el Plan Nacional e Integral de Turismo (2012-2015), donde se diseñan una serie de líneas de trabajo para su formalización, en colaboración con la Sociedad de la Información a la Sociedad Estatal para la Gestión de la Innovación y las Tecnologías Turísticas, S.A. (SEGITTUR). En el ámbito nacional, un DTI se 
concibe como "un espacio turístico innovador, accesibles para todos, consolidado sobre una infraestructura tecnológica de vanguardia que garantiza el desarrollo sostenible del territorio, facilita la interacción e integración del visitante con el entorno e incrementa la calidad de su experiencia en el destino y la calidad de vida de los residentes" (SEGITTUR, 2015).

El aspecto clave de los DTI es la integración de las TIC en la infraestructura física del destino, mediante diferentes tecnologías y sensores (Gretzel, Sigala, Xiang y Koo, 2015:180). De esta forma, para avanzar en el desarrollo de un DTI, es necesario confiar en una plataforma tecnológica que permita mejorar la experiencia turística, así como una mayor eficiencia en la gestión de la información (Buhalis y Amaranggana, 2013). En esta línea, un destino turístico se convierte en inteligente cuando hace un uso intensivo de la infraestructura tecnológica con el fin de (1) mejorar la experiencia del turista y (2) mejorar el proceso de toma de decisiones mediante la gestión de los datos (Lamsfus, Martín, Alzua-Sorzabal y Torres-Manzanera, 2015; Boes, Buhalis y Inversini, 2015; Koo, Shin, Gretzel, Hunter y Chung, 2016).

Ante estas visiones más tecnológicas, destaca el modelo de DTI propuesto por IvarsBaidal, Celdrán-Bernabeu, Mazón y Perles-Ivars (2017), fundamentado en el trabajo previo de Ivars-Baidal, Solsona y Giner (2016). Los autores reconocen las potencialidades de las TIC para configurar destinos inteligentes, pero a partir de unas condiciones previas de carácter estratégico y relacional que determinan las acciones y el alcance de la estrategia. Su modelo se compone de (1) un nivel estratégico-relacional (enfocado hacia una gobernanza sustentada en la colaboración público-privada que garantice la sostenibilidad y un entorno abierto e innovador), (2) un nivel instrumental (centrado en la conectividad y la sensorización como precursora de un sistema de información que aporte inteligencia en el proceso de toma de decisiones) y (3) un nivel aplicado (orientado al desarrollo de soluciones inteligentes para la mejora de la experiencia, marketing y gestión del destino).

En este escenario dominado por las TIC e Internet, tanto ciudades como destinos se han convertido en centros productores de datos de distinta procedencia (gobierno, ciudadanos, turistas, empresas, etc.). Surgen ahora con fuerza los movimientos "open" (government, source, software, data, etc.) como interesantes iniciativas que permiten evolucionar hacia ecosistemas innovadores que, en el caso del turismo, pueden ser la palanca de cambio hacia una mejora de la experiencia turística, al favorecer el desarrollo de servicios y productos basados en las TIC, que son la clave del turista actual.

\section{HIPÓTESIS DE PARTIDA, OBJETIVOS Y METODOLOGÍA}

Este artículo parte de dos hipótesis. En primer lugar, que la aplicación del Open Data en turismo puede generar un ecosistema innovador que mejore la experiencia turística, gracias al diseño de productos y servicios TIC. Por ejemplo, el desarrollo de aplicaciones móviles, cuyo uso ha aumentado un 11\% en 2017 (Ditrendia, 2017). En segundo lugar, que su aplicación en el ámbito del turismo es baja, probablemente motivada por una falta de conocimiento, y necesita medidas que fomenten este tipo de iniciativas.

Con la finalidad de corroborar estas hipótesis, se definen dos objetivos clave. Por una parte, (1) profundizar en su terminología, conceptos asociados y principales potencialidades 
para el turismo. Con este fin se elabora el epígrafe III, una aproximación teórico-conceptual que incluye el análisis de su origen, definiciones más utilizadas, conceptos relacionados y principales oportunidades. Por otra, conocer su grado de aplicación actual en el turismo, para así identificar posibles debilidades y proponer recomendaciones para su aplicación en turismo. Para ello, en el epígrafe IV se analizan los portales de datos abiertos de las ciudades de la Red Española de Ciudades Inteligentes (RECI). En concreto, los conjuntos de datos abiertos en turismo.

Figura 1. Esquema metodológico

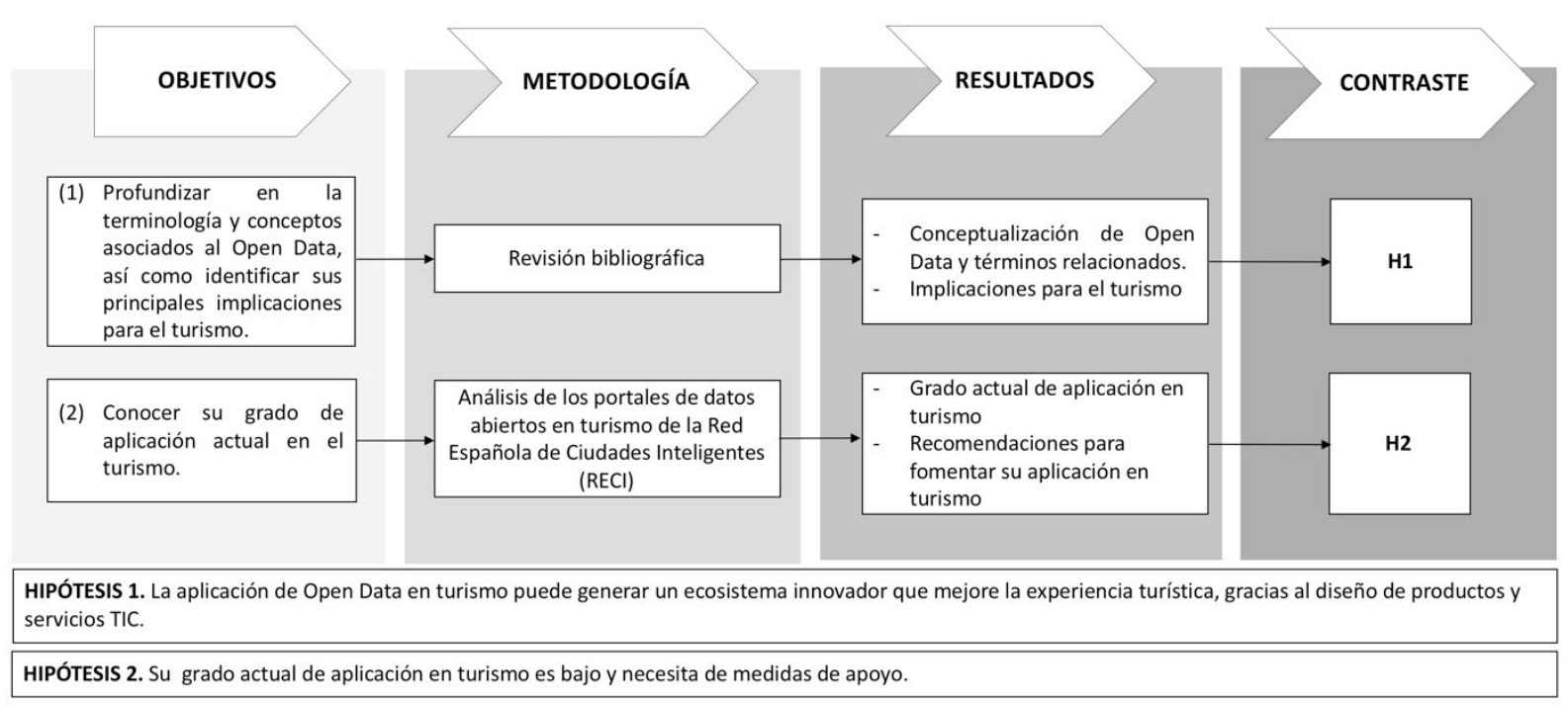

Elaboración propia

\section{OPEN DATA. UNA APROXIMACIÓN CONCEPTUAL}

Las ciudades del siglo XXI se enfrentan a distintos retos que han puesto de manifiesto la necesidad de establecer mecanismos de gestión más eficientes. En este escenario, el open government o gobierno abierto (GA, en adelante) se establece como un nuevo sistema de relaciones entre el ciudadano y la administración que, gracias a la tecnología, permite desarrollar una comunicación abierta, permanente y bidireccional. El memorando Obama (2009) es un hito elemental del GA. De acuerdo al mismo, un GA se sustenta sobre tres pilares: transparencia, colaboración y participación. Para los directivos públicos españoles que se encargan de las políticas de GA, se asocia fundamentalmente con la transparencia, el Open Data (Datos Abiertos, en castellano) la participación y la colaboración. Entre sus principales virtudes, destacan la capacidad para fomentar la transparencia y el acceso a la información, la participación y colaboración, así como la mejora de la calidad democrática (Criado y Ruvalcaba, 2016). Es por ello, que se hace imprescindible que los datos sean abiertos.

Las ciudades y los DTI se sustentan en el GA. Así, la ciudad inteligente está formada por seis pilares interconectados (Giffinger, 2007): (1) e-Gobierno y e-Gobernanza, (2) movilidad, (3) sostenibilidad ambiental, (4) capital intelectual, (5) calidad de vida y (6) desarrollo económico. Los objetivos del e-Gobierno y la e-Gobernanza son mejorar la participación ciudadana, 
la transparencia, los servicios públicos y sociales, la comunicación ciudadano-administración local y la cohesión social y territorial. Para ello pone en marcha iniciativas relacionadas con la digitalización de la administración pública, la apertura de datos, la participación activa en redes sociales, en el desarrollo web acorde con la estrategia de ciudad inteligente o el establecimiento de canales de comunicación formales e informales (Moreno, 2015: 31). No obstante, es importante subrayar que el GA va más allá del concepto de administración electrónica o e-gobierno, que simplemente trasladaba la prestación de servicios públicos al modo electrónico. Tal y como señala Curto (2017: 4), el GA supone una evolución de los principios democráticos y tiene unos objetivos mayores, como el de ser capaz de entablar una conversación permanente con los ciudadanos, tener en cuenta sus opiniones, y tomar las decisiones en función de las solicitudes recibidas.

En este proceso de apertura a la sociedad cobra gran importancia, puesto que es un elemento común a todas las iniciativas de GA, el suministro de la información pública para que todos los agentes interesados puedan hacerse un juicio de valor no sesgado. La apertura de datos es uno de los vectores asociados a la ciudad inteligente en su relación con la ciudadanía, ofreciendo datos públicos que permiten a desarrolladores y activistas trabajar en proyectos de reutilización (Fernández, 2015: 282). En este sentido, hay que tener en cuenta que las Ciudades Inteligentes están generando una gran cantidad de datos que provienen de distintas fuentes, como el loT (Perera, Zaslavsky, Christen y Georgakopoulos, 2014; Zanella, Bui, Vangelista y Zorzi, 2014).

\subsection{La revolución del dato y el Big Data}

La irrupción de los dispositivos tecnológicos (ordenadores, smartphones, smart TVs, etc.) en la vida diaria, junto con la proliferación de todo tipo de sensores (en el origen de la llamada (oT), hace que se viva un auténtico proceso de "datificación" desconocido hasta la fecha (Newell y Marabelli, 2015) y que puede definirse como la capacidad de producir datos que puedan ser leídos por un ordenador. Este proceso deriva en una gran cantidad de datos a una escala sin precedentes, que se generan diariamente y que crecen de manera exponencial, a lo que se ha denominado Big Data.

Existen diversas definiciones de Big Data, aunque una de las más aceptadas es la propuesta en Russom (2011), que se centra no sólo en términos de cantidad de datos, sino de su heterogeneidad y tiempo de procesamiento. En esta definición, el término Big Data es un conjunto de datos cuya gestión (almacenamiento, integración, recuperación y procesamiento) limita el buen funcionamiento de los recursos disponibles a través de tres dimensiones (las tres Vs del Big Data):

- Volumen: la gran cantidad de datos, que dificulta la gestión de los datos.

- Variedad: los diferentes tipos de estructuras, o ausencia de estructura, que pueden tener los datos, y que dificultan su integración.

- Velocidad: necesidad de rapidez en la generación de los datos y el acceso a los mismos.

No obstante, se ha de hablar de una cuarta V del Big Data: se debe poder obtener Valor del Big data. La definición clásica de Big Data se centra exclusivamente en el procesamiento 
de datos para su almacenamiento y su preparación para ser explotados. Sin embargo, no se aporta información acerca del potencial uso de los datos con el fin de que aporten valor. En relación al valor que pueden aportar los datos cabe destacar, dentro de este amplio concepto de Big Data, una tendencia que ha tomado mucha fuerza es la de Open Data, (Datos Abiertos, en español). Un ejemplo paradigmático de estos grandes volúmenes de datos son los producidos por las Ciudades Inteligentes, desde datos de rutas de transporte urbano o consumo energético a los datos procedentes de sensores de presencia o posicionamiento.

\subsection{Open Data. Caracterización y potencialidad}

El Open Data (OD, en adelante) son aquellos datos que cualquiera es libre de utilizar, reutilizar y redistribuir, con el único límite, en su caso, del requisito de atribución de su fuente o reconocimiento de su autoría (FEMP, 2017). Esta iniciativa comparte la filosofía de otras, como el software libre, el código abierto (open source) y el acceso libre (open access). De esta forma, el OD puede ser entendido como una tendencia actual a la apertura de datos por parte de las administraciones públicas, existiendo un amplio consenso internacional respecto a sus potenciales beneficios (Clabo y Ramos-Vielba, 2015), fundamentalmente basado en:

- Participación y colaboración ciudadana.

- La posibilidad de monitorización y readaptación de políticas públicas.

- Las nuevas oportunidades de empleo asociadas a modelos de negocio innovadores.

Desde un punto de vista económico y social, el OD es una fuente de creatividad para las personas emprendedoras y start-ups que pueden reutilizarlos para la creación de productos y servicios turísticos de valor añadido a través de modelos de negocio innovadores (COTEC, 2017; Ferro y Osella, 2013). Las empresas que apuesten por el uso de OD incorporarán un carácter innovador a sus productos y servicios que las hará diferenciarse de la competencia. Según datos del "Estudio de Caracterización del Sector Infomediario" realizado por el Observatorio Nacional de las Telecomunicaciones y para la Sociedad de la Información (ONTSI, 2016), el volumen de negocio asociado directamente a la actividad de las empresas que generan aplicaciones, productos o servicios de valor añadido destinados a terceros, a partir de OD, se sitúa entre los 1.000 y 1.200 millones de euros. Otros informes a nivel internacional hablan de que el beneficio económico (directo e indirecto) de la reutilización de OD a nivel europeo se estima en unos 200 billones de euros (1.7\% del PIB europeo) anuales (Banco Mundial, 2014).

Para la Comisión Europea (2015), en su informe "Creating Value through Open Data", los beneficios del OD son muy diversos y van desde la mejora de la eficiencia de las administraciones públicas, al crecimiento económico del sector privado y la ampliación del estado del bienestar de los ciudadano. En términos generales, el OD puede dar lugar a unos servicios públicos más eficientes que eviten gastos innecesarios, como por ejemplo, los derivados del tiempo perdido en las congestiones de tráfico o consumos energéticos innecesarios. Del mismo modo, el acceso al contenido y al conocimiento contribuye al desarrollo de servicios innovadores y la creación de nuevos modelos de negocio. Para el 2020 se estima que serán más de 100.000 los puestos de trabajo creados al amparo del OD y 1,7 billones los ahorrados a las administraciones públicas de la Unión Europea. 
EI OD dispone de licencias y formatos adecuados para su reutilización, es decir, que pueden ser accedidos, reutilizados y redistribuidos libremente, de acuerdo a unos principios básicos (Tabla 1). Las iniciativas de apertura de datos, sobre todo de las instituciones públicas, deben facilitar la reutilización de OD a todo el mundo sin restricciones técnicas ni legales (Auer, Bizer, Kobilarov, Lehman, Cyganiak e Ives, 2007).

Tabla 1. Los 8 principios básicos del Open Data

\begin{tabular}{|c|l|}
\hline COMPLETOS & $\begin{array}{l}\text { Todos los datos públicos se ponen a disposición. No están sujetos } \\
\text { a limitaciones de privacidad, seguridad o privilegios válidos. }\end{array}$ \\
\hline PRIMARIOS & $\begin{array}{l}\text { Los datos se recogen en la fuente, con el más alto nivel de } \\
\text { granularidad, no hay agregaciones o modificaciones. }\end{array}$ \\
\hline OPORTUNOS & $\begin{array}{l}\text { Los datos se pondrán a disposición tan pronto como sea necesario } \\
\text { para preservar el valor de los mismos. }\end{array}$ \\
\hline ACCESIBLES & $\begin{array}{l}\text { Los datos están disponibles para la gama más amplia de usuarios } \\
\text { con la más amplia gama de finalidades. }\end{array}$ \\
\hline PROCESABLES POR MÁQQUINAS & $\begin{array}{l}\text { Los datos se estructuran razonablemente para permitir el } \\
\text { procesamiento automatizado. }\end{array}$ \\
\hline NO DISCRIMINATORIOS & $\begin{array}{l}\text { Los datos están disponibles para cualquier persona, sin necesidad } \\
\text { de registro. }\end{array}$ \\
\hline NO PROPIETARIOS & $\begin{array}{l}\text { Los datos están disponibles en un formato sobre el cual ninguna } \\
\text { entidad tiene el control exclusivo. }\end{array}$ \\
\hline LIBRES DE LICENCIA & $\begin{array}{l}\text { Los datos no están sujetos a ningún derecho de autor, patentes, } \\
\text { marcas o regulación. Se permiten restricciones razonables de } \\
\text { privacidad y seguridad. }\end{array}$ \\
\hline
\end{tabular}

Fuente: https://opengovdata.org/

Los orígenes del OD se remontan al año 2009, cuando surgen algunas iniciativas pioneras en América del Norte y Europa, en concreto, los portales de Open Data de Estados Unidos (Data.gov, 233.306 conjuntos de datos ${ }^{1}$ ) y Reino Unido (Data.gov.uk, 44.252 conjuntos de datos) (Ferrer-Sapena y Peset, 2011). En Europa, cabe destacar el portal de la Comisión Europea Data.Europa.eu, un elemento esencial de la estrategia de la UE en materia de Open Data. Fue lanzado en el año 2012 y en la actualidad alberga 12.030 conjuntos de datos.

El marco normativo del OD en España está determinado por un conjunto de leyes de ámbito europeo, nacional y local (ordenanzas), sintetizadas en la Tabla 2. A nivel europeo, este movimiento de OD está apoyado fundamentalmente por la Directiva 2013/37/UE, del Parlamento Europeo y del Consejo, de 26 de junio de 2013, por la que se modifica la Directiva 2003/98/CE relativa a la reutilización de la información del sector público. En el ámbito nacional, por la Ley 19/2013, de 9 de diciembre, de transparencia, acceso a la información pública y buen gobierno. Sin embargo, el foco está puesto actualmente en la transparencia, ofreciendo información en formato no reutilizable (mayoritariamente en pdf o imágenes) y, sólo contadas excepciones ofrecen su información en formato procesable, a pesar de que la propia Ley

1. Consultas Web realizadas durante febrero de 2018. 
19/2013, en su Art. 5, apartado 4, sobre "Principios Generales de la publicación", establece que "La información sujeta a las obligaciones de transparencia será publicada en las correspondientes sedes electrónicas o páginas web y de una manera clara, estructurada y entendible para los interesados y, preferiblemente, en formatos reutilizables. Se establecerán mecanismos adecuados para facilitar la accesibilidad, la interoperabilidad, la calidad y la reutilización de la información publicada, así como su identificación y localización".

En España, con el objetivo de promover la apertura de datos y la reutilización de la información del sector público (RISP), el gobierno puso en marcha en 2009 el Proyecto Aporta, promovido por el Ministerio de Energía, Turismo y Agenda Digital, a través de la Entidad Pública Empresarial Red.es, y en colaboración con el Ministerio de Hacienda y Función Pública.

Nace de esta forma el portal Datos.gob.es, cuya máxima función es dar apoyo a las unidades administrativas, en las actividades técnicas y organizativas necesarias para que publiquen de acuerdo con la legislación vigente y de la forma más amigable para su reutilización, la información de acceso no restringido que recogen. Este proyecto ha sido un dinamizador importante en el impulso que la reutilización está experimentando en los últimos años en España (Marcos-Martín y Soriano-Maldonado, 2011).

Tabla 2. Marco legal del Open Data en Europa y España

\begin{tabular}{|c|c|c|}
\hline & Normativa & Objetivo fundamental \\
\hline \multirow{3}{*}{ Europa } & - Directiva 2003/98/CE & $\begin{array}{l}\text { Establecer un conjunto mínimo de normas para la reutilización } \\
\text { basadas en los principios de la transparencia, en un acceso } \\
\text { equitativo, proporcional y no discriminatorio que busca armonizar } \\
\text { mínimamente las diferentes condiciones que existan a nivel } \\
\text { comunitario. }\end{array}$ \\
\hline & - Directiva 2013/37/UE & $\begin{array}{l}\text { Modificar Directiva 2003/98/CE, tomando como referencia una } \\
\text { consulta pública realizada sobre el conjunto de actores de la } \\
\text { reutilización en Europa. }\end{array}$ \\
\hline & - Directiva Inspire & $\begin{array}{l}\text { Asegurar que las infraestructuras de datos espaciales de los Estados } \\
\text { miembros sean homogéneas, compatibles e interoperables en un } \\
\text { contexto comunitario y transfronterizo, de forma que se adopten } \\
\text { Normas de Ejecución comunes. }\end{array}$ \\
\hline \multirow{5}{*}{ España } & $\begin{array}{l}\text { - Ley } 37 / 2007 \text {, de } 16 \text { de noviembre, } \\
\text { sobre reutilización de la información } \\
\text { del sector público }\end{array}$ & $\begin{array}{l}\text { Aplicar a la reutilización de los documentos elaborados o } \\
\text { custodiados por todas las Administraciones y organismos del sector } \\
\text { público. }\end{array}$ \\
\hline & - $\frac{\mathrm{RD} 1495 / 2011 \text { sobre reutilización de la }}{\text { información del sector público }}$ & $\begin{array}{l}\text { Precisar el contenido de la Ley } 37 / 2007 \text { en el ámbito del sector } \\
\text { público estatal, regulando distintos aspectos. }\end{array}$ \\
\hline & - $\frac{\text { Norma técnica de interoperabilidad }}{\text { de reutilización de recursos de la }}$ & $\begin{array}{l}\text { Dar respuesta a las necesidades técnicas derivadas de la normativa, } \\
\text { de forma que se garantice la interoperabilidad entre las distintas } \\
\text { administraciones a la vez que se favorece su implantación. }\end{array}$ \\
\hline & $\begin{array}{l}\text { - Ley } 19 / 2013 \text { de transparencia, acceso } \\
\frac{\text { a la información pública y buen }}{\text { gobierno }}\end{array}$ & $\begin{array}{l}\text { Detallar los diferentes requisitos de publicación indicando, por } \\
\text { ejemplo, que la información será distribuida de una manera clara, } \\
\text { estructurada y entendible para los interesados y, preferiblemente, } \\
\text { en formatos reutilizables. }\end{array}$ \\
\hline & 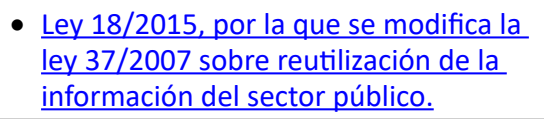 & $\begin{array}{l}\text { Ajustar y ampliar algunos apartados para adecuar las condiciones } \\
\text { que se detallan en la Directiva Europea 2013/37/EU. }\end{array}$ \\
\hline & - Ordenanzas municipales. & $\begin{array}{l}\text { Ordenanza tipo de transparencia (FEMP); Zaragoza; Santander; } \\
\text { Gijón; Oviedo; Madrid; Valladolid; Diputación Provincial de } \\
\underline{\text { Castellón; Guipúzcoa Irekia. }}\end{array}$ \\
\hline
\end{tabular}

Fuente: FEMP, 2017 


\subsection{Los portales de Open Data}

Con el fin de ofrecer el OD cumpliendo con las características legales y técnicas señaladas, los datos se publican en sitios Web, conocidos como portales de datos abiertos. Esto permite, además, que estén organizados y sean fácilmente consultados. Su principal contenido son los conjuntos de datos o datasets. Hay distintos tipos de datos, con multitud de potencialidades y aplicaciones. La Open Knowledge Foundation (2018) destaca, entre otros, los conjuntos de datos relacionados con la cultura (agendas culturales, información sobre museos, galerías, archivos, etc.), la producción científica, las finanzas (presupuestos de ingresos, de gastos, etc.), estadísticas de distintos organismos relacionadas con aspectos económicos y sociodemográficos, el tiempo meteorológico y el clima, y el medio ambiente (calidad de las aguas, calidad del aire, etc.). En cuanto a los formatos y de acuerdo al estudio de la Fundación Orange (2014), de los 50 tipos de formatos diferentes en que son originados los conjuntos de datos, los más utilizados son el formato XSL y el CSV. Destacan no obstante formatos diseñados y enfocados a la interoperabilidad (XML, JSON, RDF, etc.) y los originados en sistemas de información del territorio (DGN, SHP, etc.)

Los sistemas de gestión de datos (DMS, del inglés Data Management System) son el núcleo de los portales de datos y la herramienta utilizada para publicar, gestionar y utilizar portales de datos. Se puede comparar con sistemas de gestión de contenido (CMS, del inglés Content Management System) como Wordpress pero centrando su foco en la catalogación de los datos y no en los documentos. Para ellos, estos DMS usan estándares de catalogación de datos como DCAT (Data Catalog Vocabulary). Actualmente se pueden destacar dos DMS comerciales, denominados CKAN y Socrata, aunque existen más soluciones (incluso algunas propias de cada institución que expone sus datos en abierto) de catalogación de datos.

CKAN (del inglés, Comprehensive Knowledge Archive Network) es la herramienta para catalogación de OD más utilizada actualmente. Ha sido diseñada por OKFN y está liberada bajo una licencia de código abierto. Las funcionalidades básicas que presenta son las siguientes:

- Almacenar, gestionar y consumir conjuntos de datos.

- Integración con otros nodos de CKAN y CMS.

- Personalización y ampliación de funcionalidades.

Socrata Open Data Portal ${ }^{3}$ es una plataforma propietaria que ofrece una solución basada en la nube para la publicación de OD y su visualización. Entre sus funcionalidades tienen diferentes herramientas y soluciones para trabajar con OD, las cuales pueden complementar el Socrata Open Data Portal. Los productos más destacados son:

- Open Data API: proporciona un API para trabajar con los recursos del portal.

- Open Data Network: centraliza a todos los involucrados en el ecosistema del OD para trabajar de forma más cercana entre ellos.

- Api Foundry: framework para crear y personalizar APIs de forma rápida.

- GovStat: permite realizar análisis de los datos y comparación de resultados.

2. Comprehensive Knowledge Archive Network). Disponible en: http://ckan.org/

3. Socrata Open Data Portal. Disponible en: https://socrata.com 
De acuerdo a Datos.gob.es, España cuenta con 162 portales de OD ${ }^{4}$ de administraciones locales (92), administraciones del estado (42), administraciones autonómicas (17) y universidades (9). No obstante, cabe destacar que en ocasiones no son verdaderos portales, sino secciones de una web institucional que alberga algún tipo de conjunto de datos. Como ya se ha indicado, Estados Unidos (data.gov) y Reino Unido (Data.gov.uk) fueron los pioneros en publicar OD, ambas plataformas se publicaron en 2009.

Por otro lado, es oportuno señalar la diferencia entre portales de transparencia y portales de OD, en ocasiones confundidos. Como indica Curto (2017:390), la primera diferencia se encuentra en la temática. Así, mientras que los portales de transparencia incluyen datos financieros, presupuestarios y diferente normativa (siempre, además, se trata de datos a los que se refiere la legislación vigente en esta materia de transparencia), los portales de OD contienen información de todo tipo. Pero la diferencia más importante se encuentra en los requisitos de la información que se publica en cada una de ellos. La información publicada en un portal de transparencia no debe cumplir ningún requisito para facilitar su uso y manejo informático, ya que su objetivo es informar a la ciudadanía del buen gobierno desarrollado. La información publicada en los portales de OD sí debe facilitar la reutilización mediante la aplicación de licencias libres y el suministro de datos estructurados en formatos abiertos y no propietarios. Curto (2017) realiza un completo análisis de los portales de OD autonómicos, incluyendo un mapa web de cada uno de ellos. De acuerdo al mismo y sin ánimo de exhaustividad, dada la gran diversidad identificada, se describe en la Figura 2 un mapa web "tipo" con los elementos esenciales de un portal de OD.

Figura 2. Elementos clave de un portal de Open Data

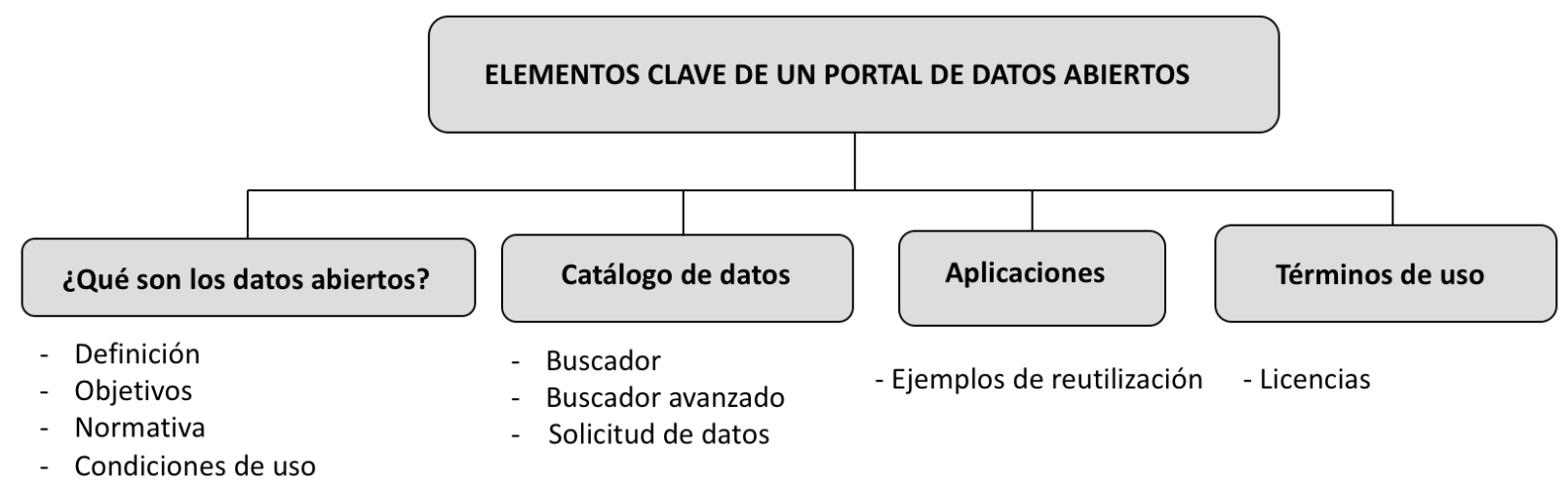

Elaboración propia a partir de Curto (2017)

\subsection{Licencias de uso y tipos de archivos asociados al Open Data}

Se denomina open data a aquellos datos en formato abierto y estándar bajo licencias de uso no restrictivas que permiten el acceso y reutilización de dicha información (datos.gob. es). Así, para lograr la reutilización de los datos, es necesario que cumplan esencialmente con dos tipos de características o requerimientos:

4. Consulta web realizada durante febrero de 2018. 
1. Características legales (LICENCIAS). Cualquier persona tiene que poder obtener los datos sin incurrir en una infracción según la legislación vigente, teniendo la seguridad que se puede trabajar con ellos y la capacidad de compartirlos. Esto se consigue poniendo los datos dentro del dominio público o aplicándoles una licencia de tipo abierto que permita el libre acceso.

2. Características técnicas (FORMATO DE ARCHIVOS). No tienen que existir obstáculos técnicos para usar los datos. Se debe asegurar que los datos están en formatos legibles que permitan una fácil utilización para el fin que fueron concebidos y una mayor reutilización para fines diferentes, además de que tienen que poder ser fácilmente procesados de manera automática.

Una licencia puede ser definida como una declaración expresa por la cual una persona recibe de otros ciertos derechos que se ejercen bajo ciertas condiciones. Por ejemplo, el derecho de uso, de copia, de distribución, de estudio o de modificación de una obra. En el contexto del OD, la aplicación de una licencia que permita la reutilización de los mismos es fundamental, más teniendo en cuenta que normalmente la legislación establece por defecto que todas las obras adquieran derechos de autor automáticamente en el mismo momento que son creadas y las cuales aplican licencias muy restrictivas, que impiden la reproducción, utilización, distribución o transformación de la obra sin el previo pago de unas tasas o el consentimiento explícito del autor.

Cada portal de OD tiene un tipo específico de licencia que va a determinar la libertad para compartir, distribuir, adaptar o utilizar los datos, así como para crear obras derivadas. De acuerdo a los condicionamientos impuestos, se distinguen diferentes licencias basadas, por ejemplo, en los fines comerciales que se desee otorgar a la información reutilizada (licencias de uso comercial frente a licencias de uso no comercial), licencias que abren más o menos los datos (licencias abiertas, licencias con previa solicitud y licencias con condiciones específicas de cada portal de OD), etc. Si bien lo ideal es que los datos tengan los menores condicionamientos posibles, no siempre es fácil encontrarlos en estas circunstancias, ya que intervienen, por ejemplo, derechos de propiedad intelectual.

Como subraya Clabo y Ramos-Vielba, (2015:7), en la actualidad existen dos tipos de licencias que regulan y promueven el libre acceso y uso de la información. Las licencias Creative Commons (CC) y las licencias Open Data Commons (ODC). Sus principales características quedan sintetizadas en la Tabla 3. A estas licencias se unen las medidas propuestas por el Real Decreto 1495/2011. Para homogeneizar las condiciones de reutilización de la información pública. Señala este Real Decreto que la información disponible es reutilizable por defecto, especificando en su artículo 7 las condiciones generales básicas a aplicar en el proceso de reutilización.

- No se podrá desnaturalizar el sentido de la información.

- Se debe citar la fuente.

- Se debe mencionar la última fecha de actualización de los datos, en caso de que esté disponible;

- Se deben conservar sin alterar de los metadatos.

- No se podrá sugerir o indicar que el titular de la información patrocina o apoya la reutilización que se realice. 
- No obstante lo anterior, el citado Real Decreto permite que los organismos públicos puedan optar por añadir, en caso necesario y de manera motivada, unas condiciones específicas para la reutilización de la información.

Tabla 3. Licencias de uso asociadas al Open Data

\begin{tabular}{|c|c|c|}
\hline & Creative Commons (CC) & Open Data Commons (ODC) \\
\hline $\begin{array}{l}\text { Esfera de } \\
\text { aplicación }\end{array}$ & Datos y documentos & Datos \\
\hline Origen & Creative Commons, 2002 & $\begin{array}{c}\text { OKFN (Open Knowledge Foundation } \\
\text { Network), } 2009\end{array}$ \\
\hline Motivación & $\begin{array}{l}\text { Conseguir una propiedad intelectual } \\
\text { más flexible. Hasta la aparición de la } \\
\text { versión } 4.0 \text {, estas licencias se centraban } \\
\text { principalmente en los contenidos. } \\
\end{array}$ & $\begin{array}{l}\text { Son las primeras licencias específicas } \\
\text { para datos abiertos, las licencias Open } \\
\text { Data Commons. }\end{array}$ \\
\hline \multirow{4}{*}{ Licencias } & $\begin{array}{l}\text { Creative Commons Zero (CCO). Ningún } \\
\text { tipo de restricción, renunciando el } \\
\text { creador a cualquier derecho sobre la } \\
\text { obra, según permita la ley. }\end{array}$ & $\begin{array}{l}\text { Open Data Commons Public Domain } \\
\text { Dedication and License (PDDL). Permite } \\
\text { difundir, reutilizar o adaptar los datos sin } \\
\text { restricción alguna. }\end{array}$ \\
\hline & $\begin{array}{l}\text { Creative Commons Reconocimiento (CC } \\
\text { BY). Solo requiere que el reutilizador } \\
\text { haga referencia a la fuente o autor } \\
\text { original. }\end{array}$ & $\begin{array}{l}\text { Open Data Commons Attribution } \\
\text { License. Al igual que la licencia de } \\
\text { Creative Commons Reconocimiento, se } \\
\text { exige la referencia a la autoría o fuente } \\
\text { de los datos para la reutilización de la } \\
\text { información. }\end{array}$ \\
\hline & $\begin{array}{l}\text { Creative Commons Reconomiento- } \\
\text { No Derivadas (CC BY-ND). Permite la } \\
\text { reutilización y difusión siempre y cuando } \\
\text { se haga referencia al autor de la misma } \\
\text { y la obra no sufra cambio o alteración } \\
\text { alguna. }\end{array}$ & $\begin{array}{l}\text { Open Data Commons Open Database } \\
\text { License (ODbL). Permite la reutilización } \\
\text { de los datos siempre que se reconozca } \\
\text { la autoría de la información original; se } \\
\text { mantenga la misma licencia en las obras } \\
\text { derivadas las cuales puede restringir su } \\
\text { uso si, además, se distribuye una versión } \\
\text { sin dichas restricciones de uso. }\end{array}$ \\
\hline & $\begin{array}{l}\text { Creative Commons Reconocimiento-No } \\
\text { Comercial (CC BY-NC).Es posible alterar } \\
\text { o difundir la obra original siempre y } \\
\text { cuando se haga referencia al autor de la } \\
\text { misma, careciendo de fines comerciales. } \\
\text { La obra derivada no está obligada a } \\
\text { mantener la misma licencia que la obra } \\
\text { original. }\end{array}$ & \\
\hline $\begin{array}{l}\text { Elementos } \\
\text { básicos de las } \\
\text { licencias }\end{array}$ & $\begin{array}{l}\text { Reconocimiento; Uso comercial/no } \\
\text { comercial; Sin/con obra derivada } \\
\text { Compartir igual. *La combinación de } \\
\text { estos elementos genera diversos tipos de } \\
\text { licencias CC. }\end{array}$ & $\begin{array}{l}\text { Reconocimiento; Compartir bajo la } \\
\text { misma licencia; Compartir;Adaptar } \\
\text { Crear; Mantener abierto; }{ }^{*} \text { La } \\
\text { combinación de estos elementos genera } \\
\text { diversos tipos de licencias ODC.. }\end{array}$ \\
\hline
\end{tabular}

Elaboración propia a partir de Clabo y Ramos-Vielba, (2015) y Datos.Gob.es. 
En cuanto a los formatos de los datos abiertos, existe un modelo de calidad para OD propuesto por Tim Berners-Lee en mayo de 2010, durante el evento Gov 2.0 Expo $2010^{5}$ y en un documento de la $\mathrm{W}^{3} \mathrm{C}^{6}$, Ilamado Esquema (o modelo) 5 estrellas $^{7}$ (Tabla 4). Este modelo establece cinco niveles de formatos etiquetados con estrellas según su la facilidad de uso por parte de los consumidores de datos.

Tabla 4. Esquema 5 estrellas del Open Data

\begin{tabular}{|c|c|}
\hline 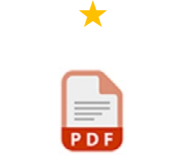 & $\begin{array}{l}\text { Los datos están disponibles en la Web, en cualquier formato no estructurado. Por } \\
\text { ejemplo, un archivo PDF, imagen o una página web HTML bajo una licencia abierta. }\end{array}$ \\
\hline 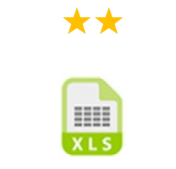 & $\begin{array}{l}\text { Los datos se publican en la Web en un formato estructurado. Esto facilita su } \\
\text { tratamiento, pero no están en formato propietario. Por ejemplo, un archivo de hoja } \\
\text { de cálculo Excel, en lugar de una tabla escaneada. }\end{array}$ \\
\hline$\stackrel{999}{\operatorname{csv}}$ & $\begin{array}{l}\text { Los datos están publicados en la web en formato estructurado, son abiertos y en } \\
\text { formato no propietario. Por ejemplo, un formato CSV en lugar de Excel. }\end{array}$ \\
\hline$\underset{R D F}{\infty}$ & $\begin{array}{l}\text { Los datos se identifican mediante URLs de manera que se pueden vincular con los } \\
\text { de cualquier otro y los usuarios pueden reutilizar parte de los datos. Se requiere la } \\
\text { utilización de formatos estándares como RDF. Adquieren significado de acuerdo a las } \\
\text { etiquetas que se utilicen para la confección del documento. }\end{array}$ \\
\hline Tूa & $\begin{array}{l}\text { Linked Open Data. Los datos están vinculados con otros datos de manera que se } \\
\text { encuentran contextualizados. Se pueden relacionar los datos originales con otros } \\
\text { nuevos. }\end{array}$ \\
\hline
\end{tabular}

Elaboración propia a partir de http://5stardata.info/es/y Curto Rodríguez (2015)

\section{DATOS ABIERTOS Y SUS IMPLICACIONES EN EL TURISMO}

Con la aparición de las TIC e Internet, los volúmenes de información que se manejan en el sector turístico han aumentado, al contrario que el control de las organizaciones turísticas sobre la misma (Buhalis y Law, 2008; Burgess, Parish y Alcock, 2011). Al mismo tiempo, las TIC se han convertido en un factor de competitividad fundamental (Buhalis y Matloka, 2011), en la medida que confieren a las organizaciones turísticas herramientas para el desarrollo de ventajas competitivas en costes, diferenciación o especialización.

Entre los subsectores turísticos destacan los destinos, que han visto cómo Internet y las TIC han guiado la evolución de los iniciales sistemas de información de los destinos (SID)

5. Tim Berners-Lee (2010). "Open, Linked Data for a Global Community". Gov 2.0 Expo 2010 http://www.youtube. com/watch?v=ga1aSJXCFe0

6. World Wide Web Consortium (W3C). Disponible en: http://www.w3.org/Designlssues/LinkedData.html

7. 5-star deployment scheme for Open Data. Disponible en: http://5stardata.info 
hasta el actual escenario, en el que a raíz de la irrupción del OD aparece una relación directa en la configuración y funciones de un SID en la actualidad, en tanto en cuanto a partir del uso de datos turísticos abiertos se pueden generar nuevas herramientas, aplicaciones y proyectos que pueden beneficiar al destino y al turista (Buhalis, 2003; Cooper y Hall, 2008. De ahí que asociar OD y turismo sea, sin duda alguna, una de las vías más claras para hablar de innovación en un destino turístico.

Ello plantea a los destinos turísticos el reto de dar un salto cualitativo en la gestión de su información y de los resultados obtenidos, no sólo desde el punto de vista de la mejora de la satisfacción de turistas y empresarios, sino de la creación de un nuevo entorno en el que se generen nuevas oportunidades de negocio vinculadas al sector turístico y a los datos.

Actualmente, la fuente de datos en un destino turístico procede básicamente de dos ámbitos. Por un lado, (1) la información generada por el turista a través de todo tipo de herramientas 2.0, aplicaciones móviles y sensores con los que interactúa. El turista digital, hiperconectado y multicanal, mantiene una estrecha vinculación con los dispositivos móviles y el uso de las tecnologías de la información y comunicación (Neuhofer, Buhalis, y Ladkin, 2015; Zheng Xiang, Magnini, y Fesenmaier, 2015; Buhalis y Foerste, 2014). La creciente innovación tecnológica en turismo (Hjalager, 2013) ha favorecido que las huellas digitales del turista (comentarios, imágenes, gasto, localizaciones, preferencias, etc.) se multipliquen a diario, así como las posibilidades de utilización de esta información por parte de los gestores, profesionales y su re-utilización por parte de los propios turistas (Pantano, Priporas y Stylos, 2017). Plataformas especializadas como TripAdvisor, Booking o MiNube, junto a redes sociales como Facebook o Instagram, ayudan a mejorar la experiencia turística (Hudson, Roth, Madden y Hudson, 2015), además de ofrecer nuevas fuentes de información que permiten caracterizar los flujos turísticos de un destino (Paldino, Bojic, Sobolevsky, Ratti, y González, 2015).

Por otro lado, (2) el DTI, que produce ahora mucha más información que el destino tradicional, gracias a la implantación de sensores y la aplicación de tecnologías como el IoT que, en general, permiten ofrecer servicios más eficientes. Se genera así un ecosistema innovador del dato en el DTI (Figura 3), caracterizado por el gran volumen de información disponible y por la intensidad de intercambio de información que se produce, especialmente a raíz de la irrupción de la Web 2.0 y de la tecnología móvil. Se trata de un elemento característico de la nueva sociedad del s. XXI que afecta a todos los ámbitos y que presenta diferentes niveles de intensidad en el intercambio y consumo de información según el sector económico que se analice, siendo el turístico uno de los principales, tal y como señala Miralbell (2007). 
Figura 3. Ecosistema innovador de datos en un destino

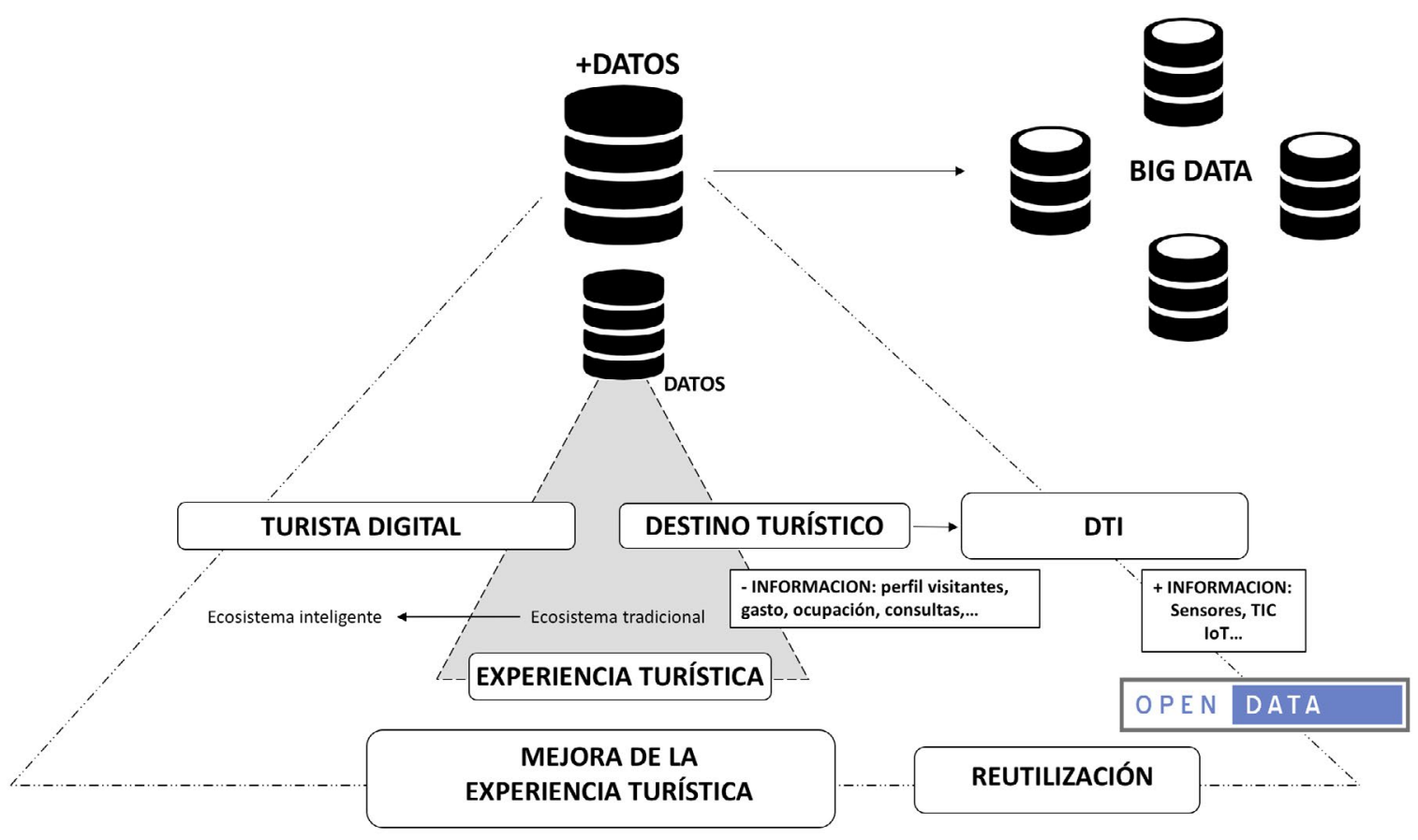

Elaboración propia

Las oportunidades que presenta este nuevo ecosistema innovador parte de la calidad y cantidad de datos que pueden obtener los destinos turísticos actualmente para reforzar su toma de decisiones, siendo un elemento diferencial del nuevo contexto y, por tanto, un factor determinante para aumentar su competitividad (Invat.tur, 2015). Para ello es necesario que los destinos turísticos conciban su gestión de la información desde una perspectiva más próxima a la necesaria convergencia de lo físico y lo digital en el marco del modelo DTI.

Toda esta gran cantidad de datos se puede englobar en el denominado Big Data, que ocupa un lugar central en el concepto de ciudad inteligente y DTI, como consecuencia de los enormes volúmenes de generación e intercambio de información que genera el medio urbano actual desde fuentes muy diversas. Este continuo aumento de la información online y de las formas de acceder a su consumo plantea tres escenarios clave para los destinos turísticos: el escenario OD, el escenario Big Data y el escenario DTI, todos ellos interrelacionados y con grandes implicaciones en el presente y futuro de la gestión de los destinos turísticos. Estos tres escenarios tienen como protagonistas a los gestores del destino, al empresariado y a los turistas, principalmente, tanto porque requieren como porque producen información de relevancia en el día a día. De estos escenarios conviene destacar el papel del OD por sus implicaciones directas con los otros dos, es decir tanto para que un destino se convierta en inteligente como para que pueda aprovechar y maximizar las utilidades del Big Data. El OD es sinónimo de transparencia, de colaboración y de participación, conceptos a los que deben enfocarse las estrategias de los destinos turísticos a largo plazo y que deben servir a los destinos para convertirse en verdaderos ecosistemas innovadores, donde sector privado y público compiten 
y colaboran al mismo tiempo para hacer crecer el destino de manera conjunta y mejorar la experiencia turística (Giner, 2017).

A pesar de su reconocido potencial a la hora de incrementar la innovación e impulsar la mejora de la experiencia y la competitividad de los destinos turísticos, llama poderosamente la atención que el OD no haya sido objeto de demasiados estudios por parte de la academia. En el ámbito internacional, Pesonen y Lampi (2016) realizan una aproximación básica, donde recogen algunas experiencias relacionadas con portales de OD y analizan el concepto desde una perspectiva general. Indican que eI OD proviene fundamentalmente de proveedores de servicios públicos y privados (organizaciones, instituciones y empresas). Los mismos autores subrayan que no existen estudios de referencia y es necesario avanzar en esta línea de investigación.

Pereira, Sousa, Barata, Oliveira y Monsieur (2015) destacan que algunas ciudades han abierto datos en turismo para promover una mayor promoción de sus recursos turísticos, gracias al sector de programadores (infomediarios) que desarrollan sus propias aplicaciones con estos datos. Resulta especialmente interesante este trabajo, porque aborda una de las limitaciones del OD y sus derivadas en el ámbito del turismo. Y es que cada ciudad está publicando datos turísticos en diferentes formatos, lo que dificulta a los desarrolladores crear las aplicaciones móviles que se nutren de estos y que, a su vez, favorecen una mejora de la experiencia turística en destino. Para solventar esta problemática los autores proponen la CitySDK Tourism API, que pretende cumplir con las necesidades de los turistas, desarrolladores y los proveedores de datos. Esta API permite el acceso a los puntos de interés (POIs), eventos e itinerarios temáticos, y uno de sus objetivos es incrementar el mercado de aplicaciones, minimizando los costes. Está disponible para las ciudades de Amsterdam, Helsinki, Lamia, Lisboa y Roma.

Para Longhi, Titz y Viallis (2014) el turismo es la industria más interesada en el OD, ya que puede facilitar a las autoridades los procesos de toma de decisiones al tiempo que favorecen la adaptación a las nuevas necesidades del turista. A este respecto, el nuevo escenario de las tecnologías móviles ha motivado unas prácticas de marketing mucho más específicas, dirigidas en tiempo real y de manera ubicua, sobre los recursos, transportes, etc. Para favorecer estas experiencias turísticas el OD es clave, ya que favorece el desarrollo de distintas aplicaciones móviles que ofrecen información contextualizada.

En el ámbito nacional, los estudios científicos relacionados con OD y turismo son todavía más limitados. El extinto Centro de Investigación Cooperativa en Turismo del País Vasco (CICtourGUNE), a través de su también extinta revista TourGUNE Journal of Tourism and Human Mobility, se aproximaba en 2013 al concepto de OD y turismo, centrándolo en el análisis del proyecto Open Data Euskadi (ODE). Tal es el caso de los trabajos de Serna, Gerrikagoitia, Murua y López-de-Ipiña (2013) y Larrinaga, Lizarralde, Serna y Guerrikagoitia (2013).

Destaca en este ámbito nacional el trabajo de los centros tecnológicos en turismo, que elaboran en 2017 el ebook "Smart Data y Open Data" (Thinktur, 2017). En este trabajo se analizan las características del Big Data y el Open Data, aportando casos de éxito que muestran la utilidad de estas tecnologías en el sector. Todos los centros tecnológicos coinciden en el hecho de que los datos son de gran utilidad y su apertura es clave para la generación de 
nuevos productos y servicios que dinamicen la economía y añadan valor al turista. A tenor de algunas de las iniciativas existentes en materia de Open Data y turismo, se puede deducir que un gran número de organismos e instituciones han hecho suyo el término, sin tener bien interiorizados los aspectos esenciales del mismo, como puede ser la reutilización de los datos. Tal y como sucede con el término "smart", los datos abiertos se han convertido en una etiqueta de moda que se aplica, en ocasiones, con demasiada rapidez y prácticamente a todo, y además, sin estar integrada en una estrategia de apertura de datos.

Tras todo este análisis, parece indiscutible que las implicaciones de la apertura de datos en el turismo derivan fundamentalmente en una mejora de la experiencia turística, que se materializa con el desarrollo de aplicaciones móviles (apps) que reutilizan y combinan los datos abiertos para ofrecer un valor añadido al turista digital. De acuerdo al Informe Mobile en España y en el Mundo (Ditrendia, 2017), España lidera el ranking mundial en penetración de móviles, con un $88 \%$ de usuarios únicos (por delante de Singapur, Italia y Japón), siendo el móvil el dispositivo más utilizado para acceder a Internet, usado ya por un $94,6 \%$ de los españoles. En este contexto, el uso de las apps móviles ha aumentado un $11 \%$ en el 2017 y las apps de movilidad y viajes son algunas de las más utilizadas por los usuarios. En España hay 27,7 millones de usuarios activos de apps. En este contexto, la apertura de datos y la generación de apps por parte del sector infomediario debe ser un elemento clave para la mejora de la experiencia y competitividad turística.

A pesar de estas potencialidades y ser España una potencia turística mundial, no se aprecia en la actualidad un elevado desarrollo aplicaciones turísticas basadas en Open Data. Gértrudix-barrio, Álvarez-García y Rajas-Fernández (2016) analizan el OD en aplicaciones móviles, haciendo hincapié en su potencialidad para mejorar los servicios a los ciudadanos. Centran su atención en el catálogo de aplicaciones del portal Datos.gob.es. De un total de 1.646 aplicaciones, tan solo 4 son de turismo, predominando con diferencia las aplicaciones de medio ambiente (1.487).

\subsection{La Red Española de Ciudades Inteligentes (RECI) y los datos abiertos en turismo}

Con el fin de avanzar en el conocimiento de los datos abiertos en turismo en España, se revisan los portales de datos abiertos de las 81 ciudades que actualmente conforman la Red Española de Ciudades Inteligentes (RECl) ${ }^{8}$, que promueve la puesta en marcha de Ciudades Inteligentes que gestionan de manera automática y eficiente las infraestructuras y los servicios urbanos, así como la mejora de la calidad de los servicios.

El objetivo de esta búsqueda es doble y queda sintetizado en la Figura 4. En primer lugar, identificar los portales de datos abiertos de estas ciudades para, a continuación, analizar sus datasets y comprobar la existencia de datos abiertos en turismo. Esta condición queda cubierta en este estudio con la existencia de una categoría específica de turismo. Con este cometido, durante febrero de 2018 se utiliza Google como buscador, donde se introduce la cadena de búsqueda ("datos abiertos", "Ayuntamiento de ciudad RECl") y se revisan los 20

8. Mapa de ciudades de la Red RECI. http://www.redciudadesinteligentes.es/images/municipios/mapa-ciudades/ $\underline{\text { miembros-reci.pdf }}$ 
primeros resultados. En caso de no aparecer el portal, se visita como última opción la web del Ayuntamiento. Todos los resultados de este proceso han sido almacenados en un documento de Excel que puede ser descargado aquí.

Figura 4. Estrategia de búsqueda portales Open Data RECl

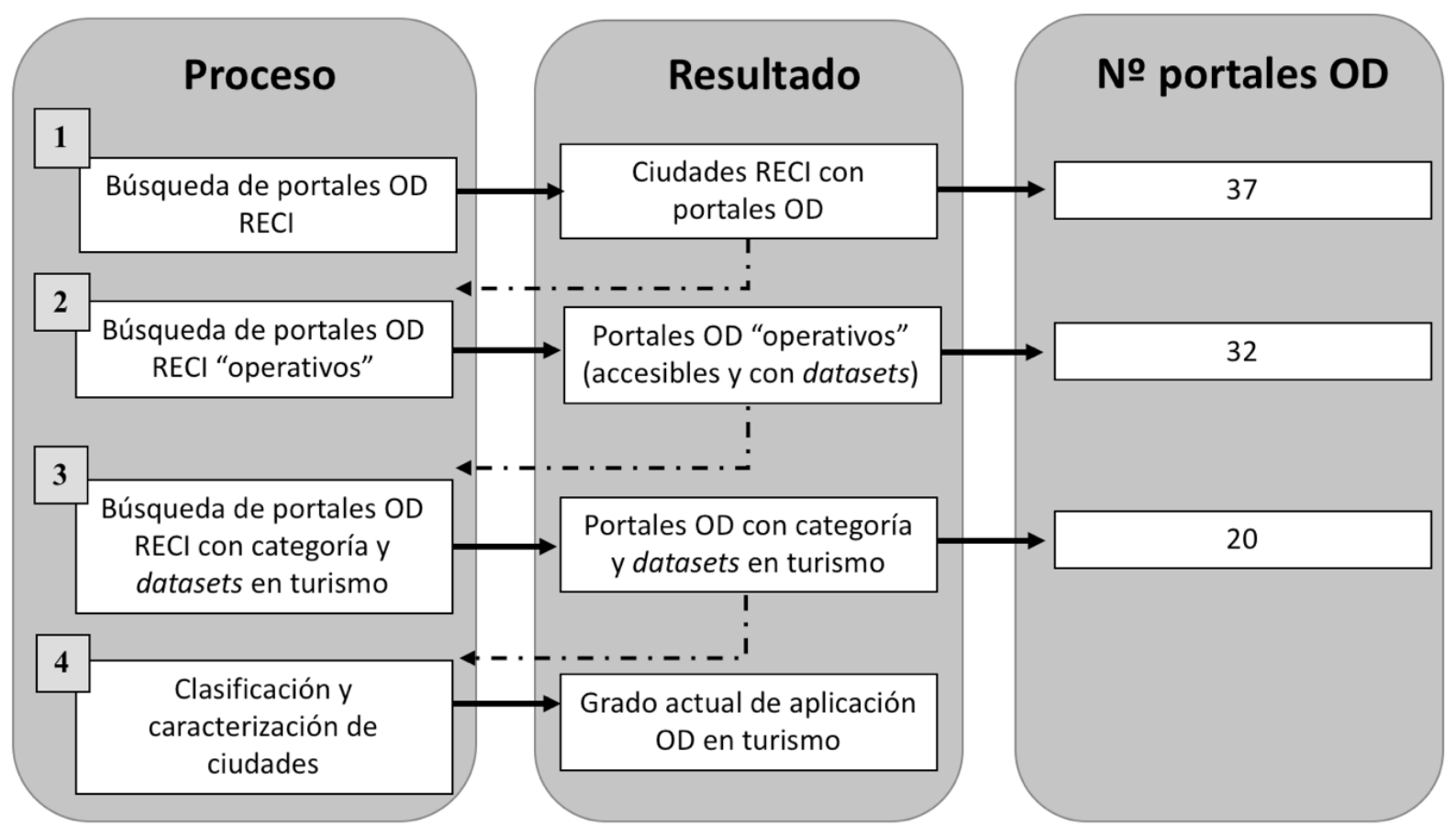

Elaboración propia

Lo primero que destaca de este análisis es que no todas las ciudades de la RECl cuentan con portales de OD, tan solo 37 ciudades disponen de portales de OD. Se han de restar a este número 5 , que se corresponden con ciudades que no tienen disponible la web en el momento de la consulta o bien no tienen conjuntos de datos publicados, por lo que son eliminadas. Resultan entonces 32 las ciudades que poseen un portal de OD con conjuntos de datos o datasets, disponibles. De ese grupo, son 20 las que publican datos abiertos en turismo, es decir, disponen de una categoría específica de turismo.

Aunque no sea el objetivo de este trabajo, es interesante mencionar que durante el proceso de búsqueda se identifican distintos portales regionales que tienen como denominador común que no permiten el filtrado de los datasets de acuerdo al organismo publicador. Sí por la categoría o tema, etiquetas, formatos, tipo de vista, destacados, más utilizados, novedades, etc. A este respecto, destacan portales con mayores posibilidades de filtrado, como Open Data Euskadi, que permite filtrar por diferentes organismos y entes públicos, entre ellos ayuntamientos, y el Portal Regional de Datos Abiertos de la Región de Murcia, que se pone a disposición de las Entidades Locales y las Universidades Públicas de la región para abrir sus datos. Este tipo de portales son una referencia a seguir. 
Con el objeto de obtener una visión general de las ciudades $\mathrm{RECl}$ que más datos publican en turismo(Gráfico 1), se procede a su categorización de acuerdo al número total de datasets publicados en la categoría turismo:

- Ciudades líderes (>10 datasets): Gijón (31), Pamplona (21), Torrent (13), Las Palma de Gran Canaria(13).

- Ciudades seguidoras (5-10 datasets): Valencia (10), Madrid (9), Molina de Segura (9), Santander (6), Sevilla (6), Zaragoza (6), Cáceres (5), Santa Cruz de Tenerife(5).

- Ciudades principiantes (<5 datasets): Lorca (4), Barcelona (3), Vitoria (2), Albacete (1), Valladolid (1), Málaga (1), Alcobendas (1), Bilbao (1).

Gráfico 1. Ranking de ciudades RECl de acuerdo a datasets en turismo

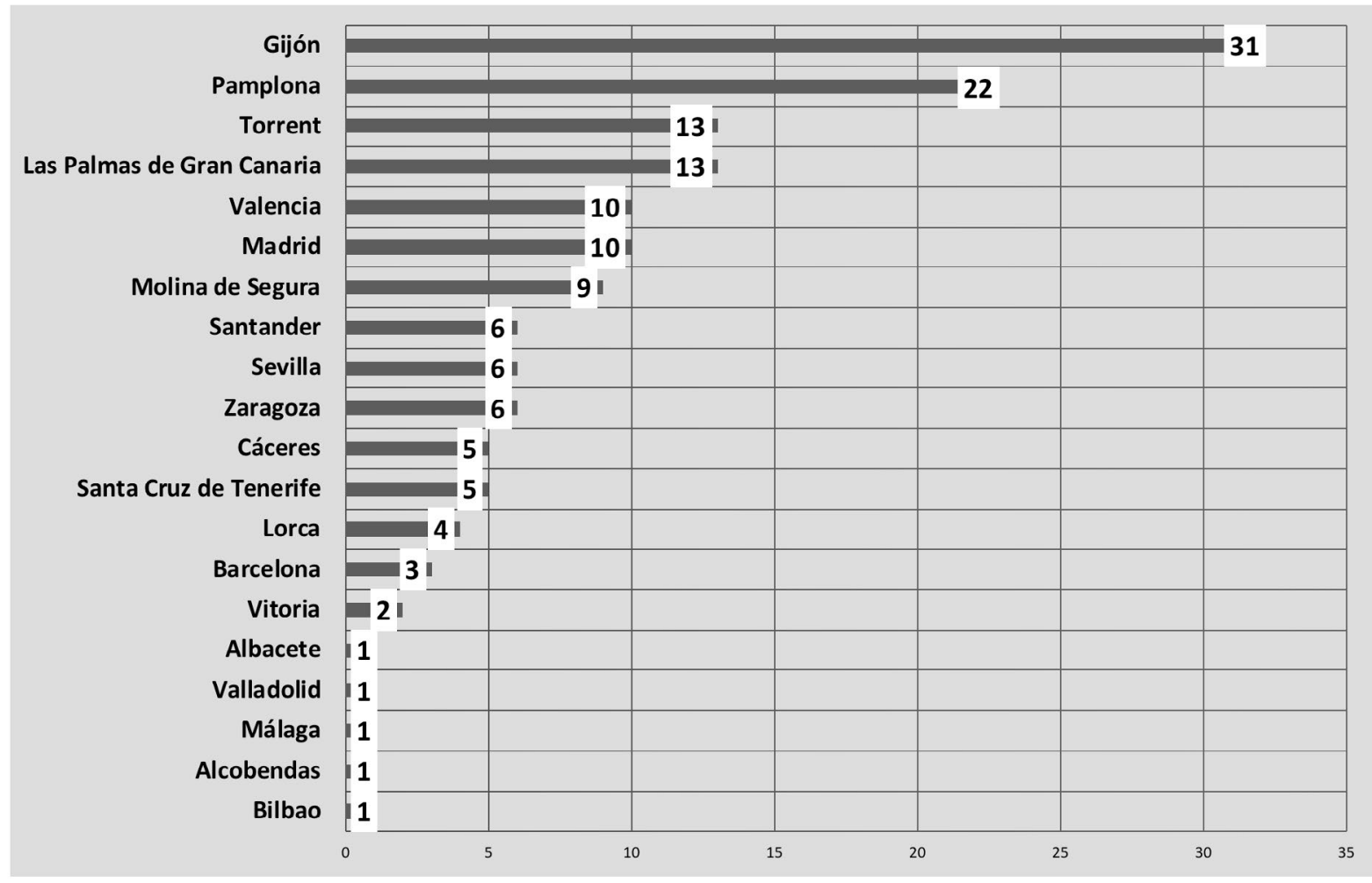

Elaboración propia

Gijón y Pamplona son con diferencia los ayuntamientos más destacados en cuanto a la publicación de datasets en turismo. Respecto al estudio de la Fundación Orange (2014:22), ambos ayuntamientos han disminuido los datasets en turismo, pasando de 35 a 31, para el caso de Gijón, y de 52 a 22, para el caso de Pamplona. Más que en el número total, la principal diferencia entre ambas ciudades es la calidad de los datos. Mientras que en Gijón tienen 5 estrellas, en Pamplona disponen de 2 estrellas. Es por ello que se puede indicar que Gijón es sin duda la ciudad de referencia en materia de Open Data y turismo. Además, Gijón actualiza 
sus datos con una frecuencia mayoritariamente mensual, mientras que los datos de Pamplona son actualizados anualmente. Un aspecto a mejorar por parte de Gijón es que no incluye descripción en sus datasets en turismo.

Del conjunto total de datasets en turismo hay que resaltar la falta de homogeneidad a la hora de entender qué es el turismo, ya que cada ciudad publica diferentes datos en esta categoría. Se intuye de esta manera una falta de conocimiento de la actividad turística y su transversalidad, en cuanto que el turismo es un conjunto de actividades o servicios. Además, tampoco se diseñan estos datasets de acuerdo al escenario turístico y sus necesidades. En este sentido, la conectividad es uno de los aspectos esenciales de la ciudad y destinos turísticos inteligentes. Tan solo Valencia y Torrent publican datos acerca de los puntos de acceso Wi-fi.

Las ciudades $\mathrm{RECl}$ que disponen de portal de datos abiertos publican un total de 4.896 datasets, de los que tan solo 150 se corresponden con datasets clasificados en turismo. Son por tanto minoritarios los conjuntos de datos agrupados en la categoría turismo. Como parte positiva destaca la alta potencialidad re-utilizadora de los datos, ya que el 55\% posee 3-4 estrellas y un $73 \%$ usa licencias Creative Commons Reconocimiento (CC BY), que cabe recordar solo requiere que el re-utilizador haga referencia a la fuente o autor original.

Gráfico 2. Calidad de los datos y licencias más utilizadas en datasets de turismo

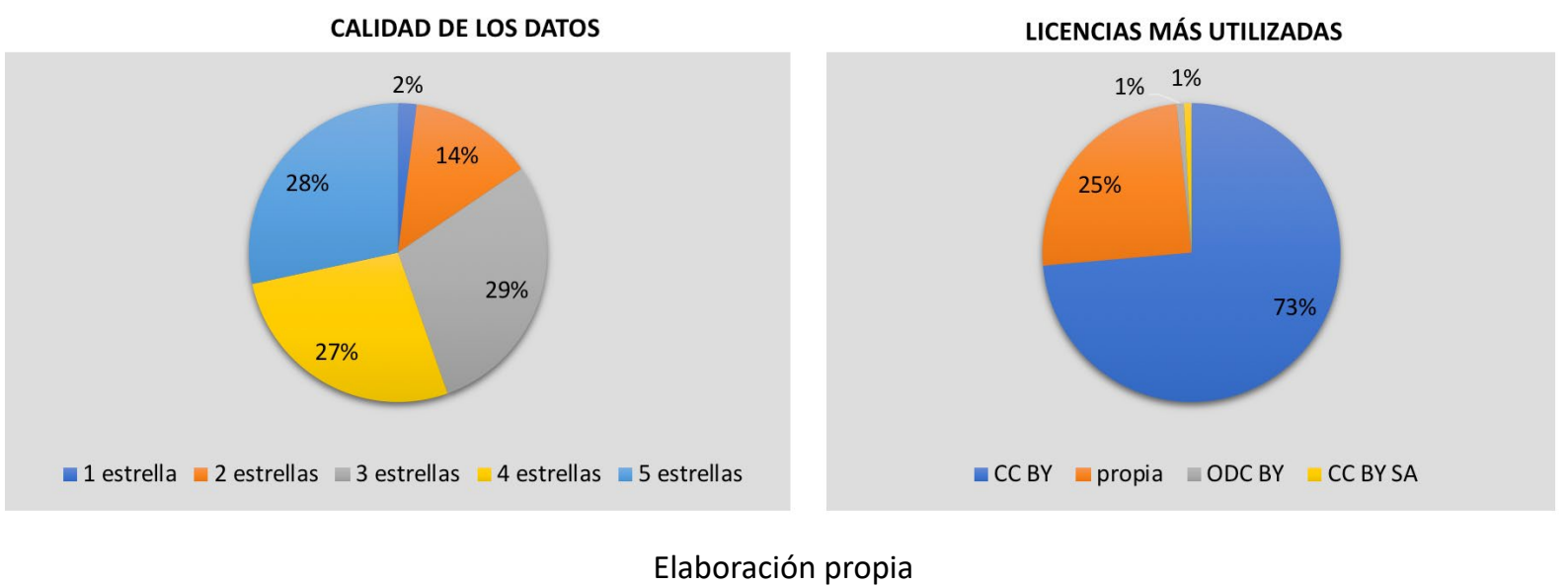

Por otro lado, respecto a las etiquetas que aplican los destinos a cada uno de estos conjuntos de datos en turismo (Figura 4) y excluyendo la etiqueta "turismo" (62), destaca su asociación a los puntos de información turística (Pit) (21), cultura (14), visitantes (12), ocio (9), alojamiento (8), encuesta (8), restaurante (6), semana santa (6), monumentos (5), museo (5) y transporte (5), principalmente. 
Gráfico 3. Etiquetas más utilizadas en los datos abiertos en turismo

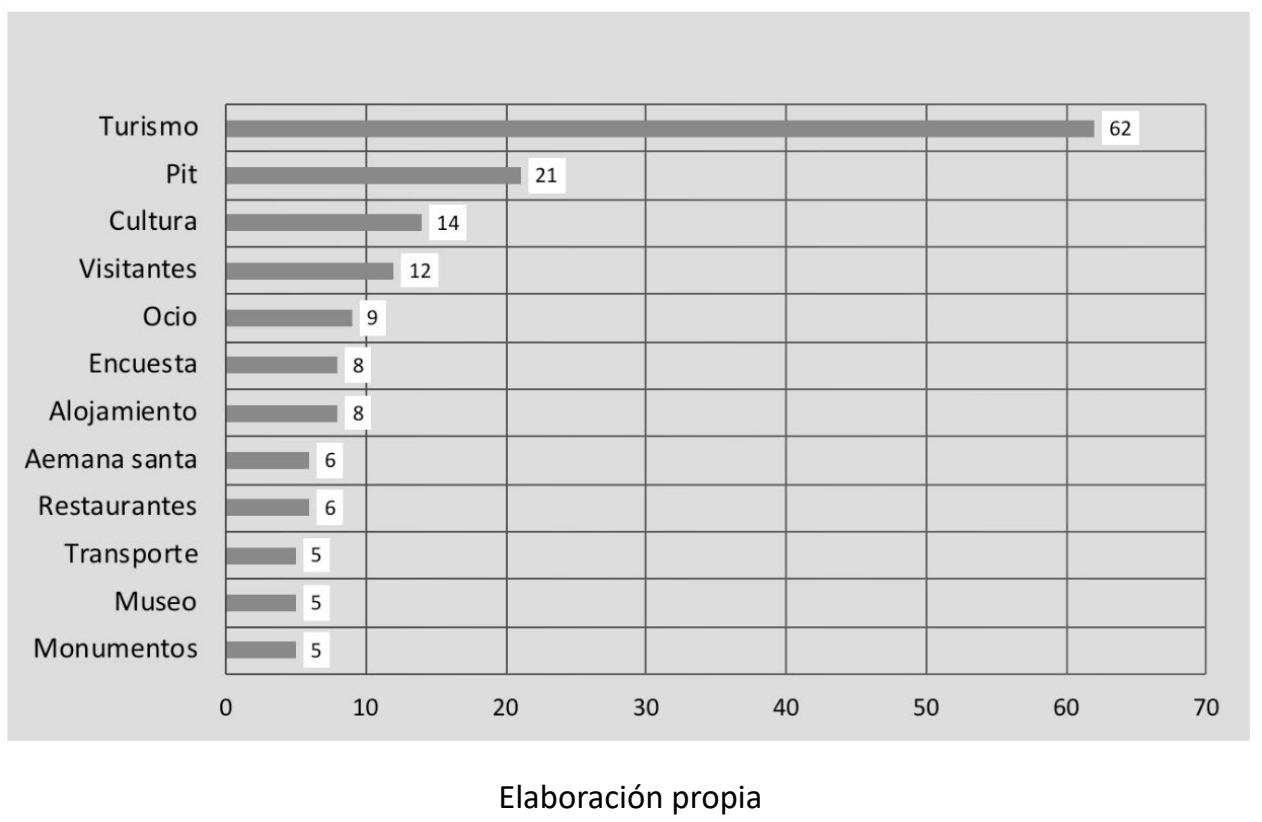

\section{CONCLUSIONES Y RECOMENDACIONES}

Los entornos urbano-turísticos del siglo XXI se enfrentan a distintas problemáticas ambientales, sociales y económicas que han motivado la aparición de nuevos enfoques de planificación y gestión. Entre éstos, destaca el enfoque Ciudad Inteligente o Smart City, que ha sido trasladado al ámbito del turismo a través del concepto DTI o smart tourism destinations. Su rasgo definitorio es la incorporación de la tecnología y la conectividad como elemento esencial, como resultado de la revolución digital y sus potencialidades a la hora de configurar ecosistemas innovadores. Entran en juego ahora tecnologías como el loT, que permite sensorizar estos entornos para obtener información en tiempo real que ayude a mejorar la gestión de las infraestructuras, servicios públicos y también la experiencia turística. A este respecto, el turista digital, hiperconectado y multicanal, mantiene una estrecha vinculación con los dispositivos móviles y el uso de las TIC, por lo que estos enfoques adquieren especial interés, al favorecer ecosistemas innovadores que encajan con las necesidades actuales de los turistas.

Pero en estos enfoques no todo son luces. Parece incuestionable que la tecnología es un instrumento que puede favorecer una mayor eficiencia en la gestión de los servicios e infraestructuras, pero aparecen interrogantes relacionados, entre otros, con el carácter sectorial de las iniciativas "Smart", la pérdida de privacidad, sus elevados costes y su identificación, en ocasiones, con campañas futuristas no relacionadas con una estrategia integral de ciudad o destino inteligente. Por ello, el foco de atención de todas estas actuaciones debe ser el ciudadano y la mejora de sus servicios y calidad de vida, teniendo siempre como pilar de referencia la mejora de la sostenibilidad, la innovación y la gobernanza.

Es un hecho que este uso intensivo de la tecnología en la ciudad inteligente y el DTI genera un gran volumen de datos, que se puede englobar en el denominado Big Data, un elemento clave de estos entornos renovados. EI OD surge ahora como un escenario directamente 
relacionado con el Big Data, la ciudad inteligente y el DTI, con grandes implicaciones para la gestión turística. Desde un punto de vista teórico, su puesta en marcha favorece la estrategia de configuración de ciudades y DTI, al convertirse en verdaderos ecosistemas innovadores, donde sector privado y público compiten y colaboran al mismo tiempo para hacer crecer el destino de manera conjunta y mejorar la experiencia turística, principalmente a través del desarrollo de aplicaciones móviles. No obstante, no se puede contrastar la hipótesis número 1: la aplicación de OD en turismo puede generar un ecosistema innovador que mejore la experiencia turística, gracias al diseño de productos y servicios TIC. El motivo es el escaso uso del OP y de su reutilización. Esta previsión teórica podrá validarse en el futuro con investigaciones específicas.

En esta misma línea, resultan altamente esclarecedoras las conclusiones obtenidas por la Fundación COTEC (2017) para el caso español, en su informe "La reutilización de datos abiertos: una oportunidad para España". Si bien España es un país de referencia en materia de publicación de datos desde el ámbito público, tan solo una pequeña proporción de los datos publicados son utilizados para la generación de servicios innovadores y, además, la gran mayoría de ellos no tienen las características necesarias para generar servicios innovadores. Entre los factores generales que pueden explicar estos bajos niveles de aplicación y de acuerdo a Janssen et al. (2016: 262-263), se encuentran un conjunto de barreras relacionadas con aspectos institucionales (Ej. Falta de liderazgo político), aspectos complejos del Open Data (Ej. Formatos archivo complejos de manejar), aspectos de uso y participación (Ej. Falta de conocimiento para hacer uso de esos datos), legislativos (Ej. Licencias limitadas), calidad de la información (Ej. Información incompleta o mal estructurada) y aspectos técnicos (Ej. Falta de apoyo para abrir datos).

Este trabajo ha realizado una aproximación inicial al grado actual de aplicación de los datos abiertos en turismo, para lo que se han analizado los portales de datos abiertos de las ciudades de la Red Española de Ciudades Inteligentes (RECI). En concreto, los datos abiertos en turismo en cada una de éstas. El resultado obtenido nos permite concluir en primer lugar que, actualmente, la apertura de datos en las Ciudades Inteligentes se encuentra en fase de desarrollo. De las 81 ciudades que conforman la RECI, tan solo 32 disponen de portales de datos abiertos operativas. De ese conjunto, 20 publican datos abiertos en turismo, es decir, tienen una categoría específica. La RECI publica un total de 4.896 datasets, únicamente 150 son clasificados en la categoría turismo. Los datos publicados en turismo son mínimos, lo que deja ver un estado embrionario respecto a las relaciones OD y turismo. Se contrasta de esta manera la hipótesis de partida número 2: su grado de aplicación actual en turismo es bajo y necesita medidas de apoyo.

Tras el análisis de la RECl y las conclusiones extraídas del marco teórico-conceptual, se sintetizan 4 recomendaciones generales y sus principales líneas de acción asociadas, para fomentar la apertura de datos en turismo.

- R1. Diseño de una estrategia Open Data enmarcada en la estrategia de ciudad - DTI. Para ello es indispensable planificar un proceso de apertura de datos debidamente secuenciado, cuyos objetivos se encuentren, además, alineados con la estrategia de ciudad inteligente o DTI. Pasos esenciales de este plan son conocer la información global disponible en el destino, así como su interés de 
apertura de acuerdo a las necesidades del destino y las necesidades del turista actual. Desde del Proyecto Aporta ${ }^{9}$ se suministra información para llevar a cabo planes de RISP (Reutilización de la Información del Sector Público), donde una administración puede plasmar en un documento su estrategia conducente al fomento de los datos abiertos. Tal es el caso de Turespaña ${ }^{10}$.

- R2. Creación de un recurso semántico que permita la catalogación de datos en turismo. Una conclusión que se extrae del estudio realizado es que cada ciudad considera diferentes conjuntos de datos dentro de la temática de turismo, por ejemplo hay ciudades que sólo consideran los punto de información turística (Ej. Su localización), mientras que otras ciudades incluyen como dato de turismo la información de la agenda cultural de la ciudad. Otras, además, no consideran los alojamientos como información de turismo, quizás influenciados por el hecho de que se trata de datos procedentes de empresas privadas y de manera generalizada no se consideran los datos de transporte como turísticos. Sin embargo, el turismo engloba a una gran diversidad de productos y servicios ligados a un conglomerado de actividades económicas. Es por ello que es importante disponer de un recurso semántico donde los conceptos que tienen que ver con el turismo estén claros y relacionados con otros conceptos, de tal manera que se puedan determinar qué datos son del dominio turístico, como primer paso para realizar una catalogación conveniente de estos datos.

- R3. Dinamizar el Open Data desde la escala regional. Los portales regionales deben configurarse como dinamizadores de la escala local, es decir, ofrecer su experiencia a los ayuntamientos para promover la apertura de datos. Por otro lado, su capacidad aglutinadora puede favorecer un mayor acceso a los datos abiertos en turismo a escala regional y local. Casos de referencia son Open Data Euskadi y el Portal Regional de Datos Abiertos de la Región de Murcia.

- R4. Promocionar la apertura de datos en turismo. Para ello se propone la creación de un portal de Open Data en turismo que, siguiendo la R2, incluya todos los conjuntos de datos relacionados con la actividad turística. Este portal podría partir como una iniciativa nacional, a liderar por el organismo oportuno, que incluya a ciudades turísticas y sus datasets en turismo.

La presente investigación se establece como un punto de partida en el análisis de las relaciones OD y turismo, y ha mostrado algunas limitaciones que deben ser consideradas. En primer lugar, los datos de aplicación de OD al turismo provienen únicamente de la $\mathrm{RECl}$, por lo que es una muestra limitada. En segundo lugar, y teniendo presente el modelo de DTI propuesto por Ivars-Baidal, Solsona y Giner (2016) e Ivars-Baidal, Celdrán-Bernabeu, Mazón y Perles-Ivars (2017), se ha enfocado el análisis hacia la categoría turismo, pero un DTI está formado por diferentes niveles que incluyen distintos tipos de datos. El objetivo era ofrecer una perspectiva general sobre el OD y su aplicación al turismo.

9. Proyecto Aporta. Disponible en http://datos.gob.es/es/documentacion/proyecto-aporta.

10. Plan RISP de Turespaña. Disponible en: https://datos.gob.es/sites/default/files/doc/file/plan risp turespana.pdf 
Entre las líneas de investigación futuras, es especialmente interesante definir unos conjuntos de datos mínimos a publicar por el DTI y la Ciudad Inteligente, así como profundizar en los resultados actuales del OD en turismo, por ejemplo el desarrollo de aplicaciones turística basadas en OD y sus singularidades.

\section{REFERENCIAS BIBLIOGRÁFICAS}

Abellá-García, A., Ortiz-de-Urbina-Criado, M. y De-Pablos-Heredero, C. (2015). The ecosystem of services around Smart cities : An exploratory analysis. Procedia-Procedia Computer Science, 64, 1075-1080. http://doi.org/10.1016/i.procs.2015.08.554

Albino, V., Berardi, U. y Dangelico, R. M. (2015). Smart Cities: Definitions, Dimensions, Performance, and Initiatives. Journal of Urban Technology, 22(1), 3-21. http://doi.org/ $10.1080 / 10630732.2014 .942092$

Auer, S. R.; Bizer, C. Kobilarov, G., Lehmann, J., Cyganiak, R. e Ives, Z. (2007). DBpedia: A Nucleus for a Web of Open Data. The Semantic Web. Lecture Notes in Computer Science 4825. p. 722.

Baggio, R. y Cooper, C. (2015). Knowledge transfer in a tourism destination: the effects of a network structure. The Service Industries Journal, (4), 145-150. http://doi. org/10.1016/j.jdmm.2015.02.001

Boes, K., Buhalis, D. e Inversini, A. (2015). Conceptualising Smart Tourism Destination Dimensions. Information and Communication Technologies in Tourism 2015 SE - 28, 391-403. http://doi.org/10.1007/978-3-319-14343-9_29

Buhalis, D. (2003). eTourism: Information Technology for Strategic Tourism Management. Ed. Prentice-Hall.

Buhalis, D. y Law, R. (2008). Progress in information technology and tourism management: 20 years on and 10 years after the Internet the state of eTourism research. Tourism Management, 29, 4, $609-623$.

Buhalis, D. y Matloka, J. (2011). Impulsar la comercialización electrónica de destinos turísticos con la personalización de contenidos: la economía de las colas largas. Estudios Turísticos, 189, 9 - 35.

Buhalis, D. y Amaranggana, A. (2013). Smart Tourism Destinations. In Information and Communication Technologies in Tourism 2014 (pp. 553-564). http://doi. org/10.1007/978-3-319-03973-2

Buhalis, D. y Foerste, M. (2014). SoCoMo marketing for travel and tourism: Empowering co-creation of value. Journal of Destination Marketing and Management, 4(3), 151161. http://doi.org/10.1016/i.jdmm.2015.04.001

Burgess, L., Parish, B. y Alcock, C. (2011). To what extent are regional tourism organisations (RTOs) in Australia leveraging the benefits of web technology for destination marketing and e-Commerce? Electronic Commerce Research, 11, 341 - 355.

Caragliu, A., Del Bo, C. y Nijkamp, P. (2011). Smart Cities in Europe. Journal of Urban Technology, 18(2), 65-82. http://doi.org/10.1080/10630732.2011.601117

Chung, N., y Koo, C. (2015). The use of social media in travel information search. Telematics and Informatics, 32(2), 215-229. http://doi.org/10.1016/j.tele.2014.08.005 
Cisco (2016). Cisco Visual Networking Index: Global Mobile Data Traffic Forecast Update, 2011-2016. Cisco. Disponible en: https://goo.gl/kha5s8. [Fecha de consulta: 28 de enero de 2018]

Clabo, N., y Ramos-Vielba, I. (2015). Reutilización de datos abiertos en la administración pública en España y uso de licencias-tipo. Revista Española de Documentación Científica, 38(3), 1-14.

Comisión Europea (2010). Europa 2020: Una estrategia para un crecimiento inteligente, sostenible e integrador. Disponible en: https://eur-lex.europa.eu/legal-content/ES/ TXT/?uri=LEGISSUM\%3Aem0028. [Fecha de consulta: 28 de enero de 2018]

Comisión Europea (2015). Creating Value through Open Data. Disponible en: https://goo. gl/7nqQGc. [Fecha de consulta: 12 de febrero de 2018]

Cooper C. y Hall M. (2008): Contemporary tourism: an international approach. Ed. BH.

Criado, J. y Ruvalcaba Gómez, E. A. (2016). ¿QUÉ ES Y QUÉ SE ENTIENDE POR GOBIERNO ABIERTO? Análisis de la percepción e implementación del Gobierno Abierto en el ámbito local español. Madrid: Laboratorio de Gobierno para la Innovación Pública.

Curto Rodríguez, R. (2015). Los portales de datos abiertos autonómicos y la rendición de cuentas. Auditoría Pública, 66, 75-83.

Curto Rodríguez, R. (2017). Datos Abiertos y rendición de cuentas en las comunidades autónomas españolas. Niveles de divulgación y determinantes (Tesis Doctoral). Universidad de Oviedo.

Ditrendia (2015). Informe Mobile en España y en el Mundo 2017. Disponible en: https:// www.amic.media/media/files/file 352 1289.pdf. [Fecha de consulta: 17 de febrero de 2018].

FEMP (2017). Datos Abiertos. Guía estratégica para su puesta en marcha. Madrid.

Fernández-Güell, J. M. (2015). Ciudades Inteligentes. La mitificación de las nuevas tecnologías como respuesta a los retos de las ciudades contemporáneas. Economía Industrial, 17-28.

Fernández González, M. (2015). La Smart City como imaginario socio-tecnológico digital. La construcción de la utopía urbana digital. Universidad del País Vasco.

Ferrer-Sapena, A., y Peset, F. (2011). Acceso a los datos públicos y su reutilización : open data y open government. El profesional de la Información, 4-5. http://doi.org/10.3145/ epi.2011.may.03

Ferro, E. y Osella, M. (2013). Eight business model archetypes for PSI Re-Use. In Open Data on the Web Workshop, Google Campus, Shoreditch, London.

Fundación COTEC para la Innovación (2017): La reutilización de datos abiertos: una oportunidad para España. Disponible en: http://informecotec.es/media/INFORME REUTILIZACIONDE-DATOS.pdf. [Fecha de consulta: 17 de abril de 2018]

Fundación Orange (2014). Datos abiertos en las Comunidades Autónomas y sus mayores ayuntamientos 2014 Resumen ejecutivo. Disponible en: https://www.proyectosfundacionorange.es/docs/eE2014/Datos Abiertos 2014 resumen ejecutivo.pdf. [Fecha de consulta: 4 de febrero de 2018]

Gértrudix-Barrio, M., Álvarez-García, S., y Rajas-Fernández, M. (2016). Open Data in Mobile Applications, New Models for Service Information. Journal of Communication, 117-131. 
Giffinger, R. (2007). Smart cities Ranking of European medium-sized cities. October (Vol. 16). Disponible en: http://linkinghub.elsevier.com/retrieve/pii/S026427519800050X. [Fecha de consulta: 2 de diciembre de 2017]

Giner, D. (2017): Open data en la información turístico: el caso de la Comunitat Valenciana, en Smart Data y Open Data (Thinktur, 2017). Disponible en: https://goo.gl/dQhSof. [Fecha de consulta: 12 de febrero de 2018]

Gretzel, U., Sigala, M., Xiang, Z., y Koo, C. (2015). Smart tourism : foundations and developments, 179-188. http://doi.org/10.1007/s12525-015-0196-8

Guo, Y., Liu, H., y Chai, Y. (2014). The embedding convergence of smart cities and tourism internet of things in China: An advance perspective. Advances in Hospitality and Tourism Research (AHTR), 2(1), 54-69.

Hedman, J., Srinivasan, N., y Lindgren, R. (2013). T He S Ociomateriality of I Nformation S Ystems : Icis, 38(3), 809-830.

Hjalager, A.-M. (2013). 100 Innovations That Transformed Tourism. Journal of Travel Research, 54(1), 3-21. http://doi.org/10.1177/0047287513516390

Huang, C. D., Goo, J., Nam, K., y Woo, C. (2017). Information y Management Smart tourism technologies in travel planning : The role of exploration and exploitation. Information $y$ Management, 54(6), 757-770. http://doi.org/10.1016/i.im.2016.11.010

Hudson, S., Roth, M. S., Madden, T. J., y Hudson, R. (2015). The effects of social media on emotions, brand relationship quality, and word of mouth: An empirical study of music festival attendees. Tourism Management, 47, 68-76. http://doi.org/10.1016/i. tourman.2014.09.001

Instituto Valenciano de Tecnologías Turísticas (Invat.tur) - Agència Valenciana del Turisme (2013). Proyecto Destinos Turísticos Inteligentes Comunitat Valenciana - DTICV. Disponible en: http://goo.gl/MzSMKp. [Fecha de consulta: 12 de febrero de 2018]

Ivars-Baidal, J. A., Celdrán-Bernabeu, M. A., Mazón, J. N., y Perles-Ivars, Á. F. (2017). Smart destinations and the evolution of ICTs: a new scenario for destination management? Current Issues in Tourism, 3500(October), 1-20. http://doi.org/10.1080/13683500.20 17.1388771

Ivars Baidal, J. A., Solsona Monzonís, F. J., y Giner Sánchez, D. (2016). Gestión turística y tecnologías de la información y la comunicación (TIC): El nuevo enfoque de los destinos inteligentes, 62(2), 327-346.

Janssen, M., Charalabidis, Y., Zuiderwijk, A., Janssen, M., Charalabidis, Y., y Zuiderwijk, A. (2016). Benefits, Adoption Barriers and Myths of Open Data and Open Government Benefits, Adoption Barriers and Myths of Open Data and Open Government, 530(June). http:// doi.org/10.1080/10580530.2012.716740

Kitchin, R. (2014). Making sense of smart cities: addressing present shortcomings. Cambridge Journal of Regions, Economy and Society, 8(1), 131-136. http://doi.org/10.1093/cjres/ $\underline{\mathrm{rsu} 027}$

Komninos, N., Schaffers, H., y Pallot, M. (2011). Developing a Policy Roadmap for Smart Cities and the Future Internet. eChallenges e2011, 1-8. http://doi.org/10.1109/ MCOM.2013.6525605 
Koo, C., Shin, S., Gretzel, U., Hunter, W. C., y Chung, N. (2016). Conceptualization of Smart Tourism Destination Competitiveness. Asia Pacific Journal of Information Systems, 26(4), 561-576. http://doi.org/10.14329/apjis.2016.26.4.561

Lamsfus, C., Martín, D., Alzua-Sorzabal, A., y Torres-Manzanera, E. (2015). Smart Tourism Destinations: An Extended Conception of Smart Cities Focusing on Human Mobility. In Information and Communication Technologies in Tourism 2015 (pp. 363-375). http:// doi.org/10.1007/978-3-319-14343-9 27

Larrinaga, F., Lizarralde, O., Serna, A., y Guerrikagoitia, J. K. (2013). Caso de uso de Open Data y Linked Data en Turismo. TOURGUNE Journal of Tourism and Human Mobility, (1), 1-9.

Libelium (2017): Top 50 IoT Sensor Applications Ranking. Disponible en: http://www.libelium.com/resources/top 50 iot sensor applications ranking/. [Fecha de consulta: 3 febrero de 2018]

Longhi, C., Titz, J., y Viallis, L. (2014). Open Data: Challenges and Opportunities for the Tourism Industry. In M. M. Mariani, R. Baggio, Buhalis, y Longhi (Eds.), Tourism Management, Marketing, and Development (pp. 55-76). New York.

March, H., y Ribera-Fumaz, R. (2014). Smart contradictions: The politics of making Barcelona a Self-sufficient city. European Urban and Regional Studies, 1-15. http://doi. org/10.1177/0969776414554488

Marcos-Martín, C., y Soriano-Maldonado, S.-L. (2011). Reutilización de la información del sector público y. El Profesional de La Información, 291-297. http://doi.org/10.3145/ epi.2011.may.07

Ministerio de Energía, Turismo y Agenda Digital (2017). Plan Nacional de Territorios Inteligentes (2017-2020). Madrid. Dlsponible en: https://goo.gl/6w6jgT. [Fecha de consulta: 28 de enero de 2018]

Ministerio de Industria, Energía y Turismo (2015). Plan Nacional de Ciudades Inteligentes. Disponible en https://goo.gl/8jrYXi. [Fecha de consulta: 2 de diciembre de 2017]

Ministerio de Industria, E. y T., y Públicas, M. de H. y A. (2013). Agenda Digital para España, 1-59. Disponible en: https://goo.gl/MwPDbA. [Fecha de consulta: 24 de noviembre de 2017]

Miralbell, O. (2007). Gestión de Oficinas de Turismo. Ed. UOC.

Moreno Alonso, C. (2015). Desarrollo de un modelo de evaluación de ciudades basado en el concepto de Ciudad Inteligente (Smart City). Universidad Politécnica de Madrid.

Nam, T., y Pardo, T. A. (2011). Conceptualizing Smart City with Dimensions of Technology, People, and Institutions (pp. 282-291). The Proceedings of the 12th Annual International Conference on Digital Government Research. http://doi.org/10.1145/2037556.2037602

Newell, S., y Marabelli, M. (2015). Strategic opportunities (and challenges) of algorithmic decision-making: A call for action on the long-term societal effects of "datification." Journal of Strategic Information Systems, 24(1), 3-14. http://doi.org/10.1016/i.jsis.2015.02.001

ONU-HABITAT. (2016). Reporte Ciudades del Mundo 2016. Programa de las Naciones Unidas para los Asentamientos Humanos (ONU-Habitat). Disponible en: http://nua.unhabitat. org/uploads/Reportedelasciudades2016.pdf. [Fecha de consulta: 15 de enero de 2018]

ONTSI (2017). Indicadores destacados de la Sociedad de la Información. Disponible en: http:// www.ontsi.red.es/ontsi/es/content/indicadores-destacados-de-la-sociedad-de-la-informaci\%C3\%B3n-en-espa\%C3\%B1a-abril-2018. [Fecha de consulta: 17 de febrero de 2018] 
Paldino, S., Bojic, I., Sobolevsky, S., Ratti, C., y González, M. C. (2015). Urban magnetism through the lens of geo-tagged photography. EPJ Data Science, 4(1), 1-17. http://doi. org/10.1140/epjds/s13688-015-0043-3

Pantano, E., Priporas, C.-V., y Stylos, N. (2017). "You will like it!" using open data to predict tourists' response to a tourist attraction. Tourism Management, 60, 430-438. http:// doi.org/10.1016/j.tourman.2016.12.020

Pereira, R. L., Sousa, P. C., Barata, R., Oliveira, A., y Monsieur, G. (2015). CitySDK Tourism API building value around open data. Journal of Internet Services and Applications. http:// doi.org/10.1186/s13174-015-0039-z

Perera, C., Zaslavsky, A., Christen, P., y Georgakopoulos, D. (2014). Sensing as a Service Model for Smart Cities Supported by Internet of Things, 1-12. https://doi.org/10.1002/ $\underline{\text { ett. } 2704}$

Pesonen, J. A., y Lampi, M. (2016). Utilizing open data in tourism. In ENTER 2016 Conference on Information and Communication Technologies in Tourism.

Pierce, P., Ricciardi, F., y Zardini, A. (2017). Smart cities as organizational fields: A framework for mapping sustainability-enabling configurations. Sustainability (Switzerland), 9(9), 1-21. http://doi.org/10.3390/su9091506

PwC, S. P. de, y School, I. B. (2015). Smart cities. La transformación digital de las ciudades. Disponible en: https://goo.gl/YGZhCP. [Fecha de consulta: 5 de octubre de 2017]

Russom, P. (2011). Big data analytics. TDWI Best Practices Report, Fourth Quarter

SEGITUR (2015). Informe destinos turísticos inteligentes: construyendo el futuro. Disponible en: https://goo.gl/eMtNRh. [Fecha de consulta: 15 de enero de 2018]

Serna, A., Gerrikagoitia, J. K., Murua, I., y López-de-Ipiña, D. (2013). Open Data turismo. TourGUNE Journal of Tourism and Human Mobility, (1), 1-15.

Vanolo, A. (2014). Smartmentality: The Smart City as Disciplinary Strategy. Urban Studies, 51(5), 883-898. http://doi.org/10.1177/0042098013494427

Villarejo Galende, H. (2015). Smart cities: Una apuesta de la Unión Europa para mejorar los servicios públicos urbanos. Revista de Estudios Europeos, (66), 25-51.

World Bank (2014). Open data for economic growth. Disponible en: https://goo.gl/6z7sQM. [Fecha de consulta: 17 de diciembre de 2017]

Xiang, Z., Magnini, V. P., y Fesenmaier, D. R. (2015). Information technology and consumer behavior in travel and tourism: Insights from travel planning using the internet. Journal of Retailing and Consumer Services, 22, 244-249. http://doi.org/10.1016/i. iretconser.2014.08.005

Zanella, A., Member, S., Bui, N., Castellani, A., Vangelista, L., Member, S., y Zorzi, M. (2014). Internet of Things for Smart Cities, 1(1), 22-32. 